\title{
Novel Approach to the Treatment of Gypseous Soil-Induced Ettringite Using Blends of Non-Calcium-Based Stabilizer, Ground Granulated Blast-Furnace Slag, and Metakaolin
}

\author{
Khaled Ibrahim Azarroug Ehwailat, Mohd Ashraf Mohamad Ismail * and Ali Muftah Abdussalam Ezreig \\ School of Civil Engineering, Engineering Campus, Universiti Sains Malaysia, \\ Nibong Tebal 14300, Seberang Prai Selatan, Pulau Pinang, Malaysia; Khaledazrog@student.usm.my (K.I.A.E.); \\ Aliezreig@student.usm.my (A.M.A.E.) \\ * Correspondence: ceashraf@usm.my
}

Citation: Ehwailat, K.I.A.; Mohamad Ismail, M.A.; Ezreig, A.M.A. Novel Approach to the Treatment of Gypseous Soil-Induced Ettringite Using Blends of Non-Calcium-Based Stabilizer, Ground Granulated Blast-Furnace Slag, and Metakaolin. Materials 2021, 14, 5198. https:// doi.org/10.3390/ma14185198

Academic Editors: Rajeev Roychand, Souradeep Gupta and Mohammad Saberian Boroujeni

Received: 16 August 2021

Accepted: 8 September 2021

Published: 10 September 2021

Publisher's Note: MDPI stays neutral with regard to jurisdictional claims in published maps and institutional affiliations.

Copyright: (c) 2021 by the authors. Licensee MDPI, Basel, Switzerland. This article is an open access article distributed under the terms and conditions of the Creative Commons Attribution (CC BY) license (https:/ / creativecommons.org/licenses/by/ $4.0 /)$.

\begin{abstract}
Gypseous soil is one type of expansive soil that contains a sufficient amount of sulphate. Cement and lime are the most common methods of stabilizing expansive soil, but the problem is that lime-treated gypseous soil normally fails in terms of durability due to the formation of ettringite, a highly deleterious compound. Moisture ingress causes a significant swelling of ettringite crystals, thereby causing considerable damage to structures and pavements. This study investigated the suitability of various materials (nano-Mg oxide (M), metakaolin (MK), and ground granulated blastfurnace slag (GGBS)) for the stabilization of gypseous soil. The results showed soil samples treated with 20\% M-MK, M-GGBS, and M-GGBS-MK to exhibit lower swelling rates $(<0.01 \%$ change in volume) compared to those treated with $10 \%$ and $20 \%$ of lime after 90 days of curing. However, soil samples stabilized with $10 \%$ and $20 \%$ binder of [(M-MK), (M-GGBS), and (M-GGBS-MK)] exhibited higher strengths after 90 days of soaking (ranging from 0.96-12.8 MPa) compared to those stabilized with $10 \%$ and $20 \%$ lime. From the morphology studies, the SEM and EDX analysis evidenced no formation of ettringite in the samples stabilized with M-MK-, M-GGBS-, and M-GGBS-MK. These results demonstrate the suitability of M-MK, M-GGBS, and M-GGBS-MK as effective agents for the stabilization of gypseous soil.
\end{abstract}

Keywords: sulphate-bearing soil; soil stabilization; ettringite; gypseous soil; calcium-based stabilizer; non-calcium-based stabilizer

\section{Introduction}

Most of the geotechnical problems are believed to be caused by weak soils with low strength and high compressibility; such soils must be treated with suitable stabilizers/solidifiers to enhance their load-bearing capacity [1,2]. This deterioration in strength is clearly observed in the sulphate-bearing soil. Sulphate is a soil anion that forms from the dissolution of certain minerals like sodium sulphate $\left(\mathrm{Na}_{2} \mathrm{SO}_{4}\right)$, gypsum $\left(\mathrm{CaSO}_{4} \cdot 2 \mathrm{H}_{2} \mathrm{O}\right)$, magnesium sulphate $\left(\mathrm{MgSO}_{4}\right)$, anhydrite $\left(\mathrm{CaSO}_{4}\right)$, and barite $\left(\mathrm{BaSO}_{4}\right)$. Gypsum remains the major form of sulphate found in soil; however, sulphate ions are also sourced from the oxidation of certain soil minerals, such as pyrite $\left(\mathrm{FeS}_{2}\right)[3,4]$. Sulphate-bearing soil, also known as gypseous soil, has a high capacity for swelling and a low strength when wet. This soil causes serious damage to structures, such as roads, airports, single-storey buildings, and garden walls [5-7].

Soil stabilization is the alteration of the undesired soil characteristics through certain chemical and physical processes to meet specific engineering purposes [8]. Despite the availability of numerous methods of soil stabilization, chemical stabilization with additives remains the common way of preventing soil swelling with additives, with lime and cement being the most utilized chemical additives for soil stabilization $[1,3,9]$.

The treatment of sulphate-rich soil with lime or cement has been reported to cause volume expansion [3,5,7,10-12]. The three main stages of lime-soil reaction are cation ex- 
change, flocculation, and pozzolanic reaction $[7,13]$. Furthermore, it has been demonstrated that soil contains clay ( $>10 \mathrm{wt}$ dry soil weight) and $>1 \%$ sulphate content after stabilization with cement or lime [4]. Clay releases ammonia at $\mathrm{pH}$ values $>10.5$ and this ammonia interacts with $\mathrm{Ca}^{2+}$ (contained in lime or cement), soil sulphate ions, and available soil water to form calcium silicate trisulphate hydrate (ettringite) [11,14-16]. This ettringite can be converted to calcium-silicate-hydroxide-sulphate-carbonate-hydrated material (thaumasite) at temperatures $<15{ }^{\circ} \mathrm{C}$ [17-19]. The reaction of sulphate-rich soil with calcium-based soil stabilizers is explained in Figure 1.

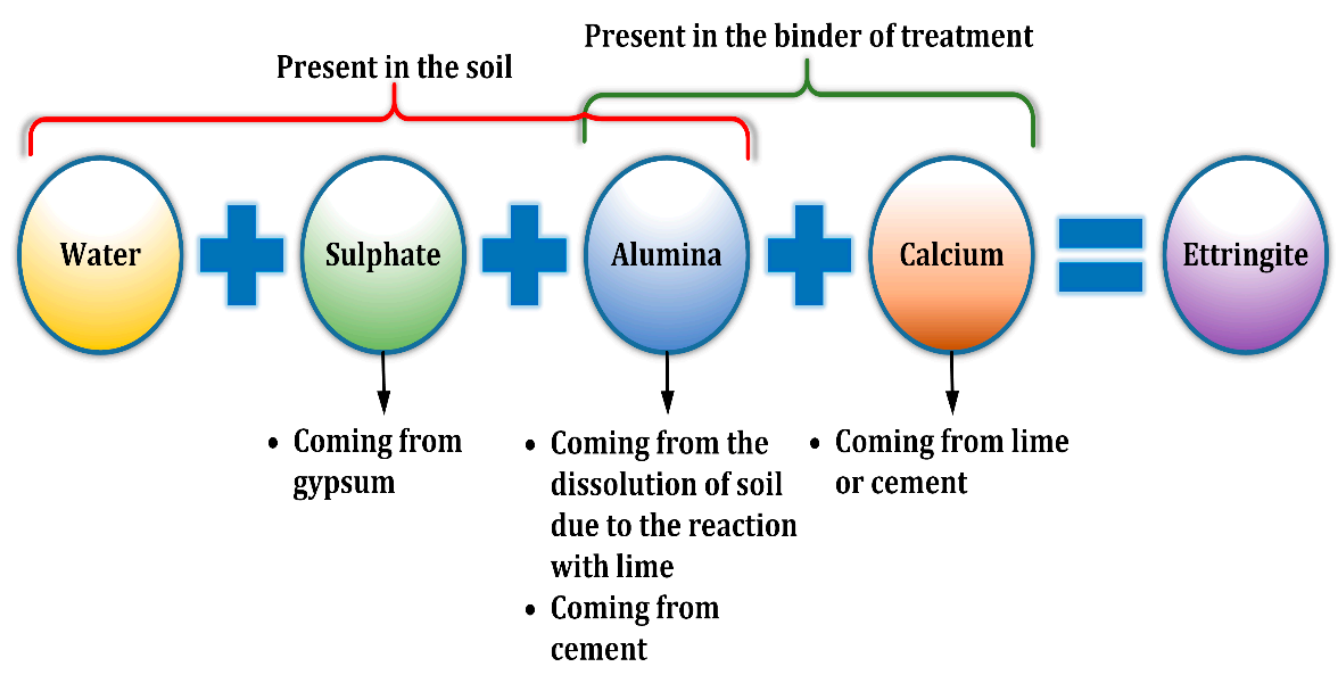

Figure 1. Schematic explaining the reaction of sulphate-bearing soil treated by cement and lime.

Ettringite forms fibrous crystals and damages the soil structure through mineral expansion during its precipitation. These sulphate minerals expand significantly when subjected to the hydration process $[19,20]$. Both hydration reactions and crystal growth causes significant heaving in sulphate-rich soils [21,22]. Sulphate-containing clay soils cause swelling with the application of calcium-based soil stabilizers. Furthermore, the destruction of calcium aluminosilicate hydrates $(\mathrm{CSH})$ causes a reduction in long-term strength [23].

Civil engineers have recently focused on the development of building materials with low cement contents as a way of reducing greenhouse emissions, climate changes, and carbon footprint of the industry. The processes involved in the production of lime and cement contribute significantly to environmental pollution. For instance, the production of 1 ton of cement leads to the emission of almost 0.95 tons of $\mathrm{CO}_{2}$ and requires almost $5000 \mathrm{MJ}$ of energy to complete [2,24-26]; for lime production, these values are $\sim 0.79$ tons of $\mathrm{CO}_{2}$ and $\sim 3200$ MJ of energy [27]. This demands the consideration of waste materials as a complete or partial replacement for conventional binders, as proposed by various researchers. GGBS is a waste material from the iron industry and has been considered a suitable material for soil stabilization. In terms of $\mathrm{CO}_{2}$ emissions and energy consumption, producing 1 ton of GGBS requires only $1300 \mathrm{MJ}$ of energy and emits only 0.07 ton of $\mathrm{CO}_{2}$ [28].

Novel methods should be able to repress heaving and ettringite formation in sulphaterich soils. Materials that exhibit pozzolanic properties, such as GGBS and MK are believed to be suitable sulphate soil stabilizers, because such materials generally consume lime, thereby reducing its availability for the formation of expansive products while enhancing the strength of the soil.

Metakaolin is a highly pozzolanic, reactive, and supplementary cementitious material that adapts to ASTM C 618 [29] and AASHTO M295 specification [30]. It is unique because it is neither an industrial by-product nor completely natural. Metakaolin is manufactured from natural minerals specifically for cementing purposes; it is manufactured from kaolin clay that has been calcined under high temperature $\left(600-800^{\circ} \mathrm{C}\right)$ to create an amorphous 
aluminosilicate that is reactive in concrete [31-33]. Sulphate ions intrusion into concrete weakens the cement paste-aggregate bond, thereby causing severe damages, such as expansion and extensive cracking. An increase in MK content (5-20\%) has been reported to reduce mortar expansion when used with intermediate and high $\mathrm{C}_{3} \mathrm{~A}$ content cement [33].

GGBS can serve as partial or complete replacement for cement or lime to prevent or reduce ettringite formation in stabilized sulphate soils. The alumina and silica contents of GGBS can quickly react with the calcium content in soil to form a cementitious gel, thereby reducing or preventing ettringite formation $[8,28,34]$. GGBS can also reduce water availability and permeability through the formation of a denser cementitious matrix, which improves resistance to both external and internal sulphate attacks $[28,35,36]$.

Reactive magnesia (M) is a more effective substance in GGBS activation compared to lime, as it facilitates a higher rate of strength development [6,8,37-40]. Reactive $\mathrm{M}$ is commonly obtained from the calcination of magnesite at temperature range of $700-800{ }^{\circ} \mathrm{C}$ and high capacity in absorbing carbon dioxide $\left(\mathrm{CO}_{2}\right)[2,41]$. Reactive $\mathrm{M}$ is used at low concentration during GGBS activation, hence the overall $\mathrm{CO}_{2}$ emission during the reaction of $\mathrm{M}$ with GGBS is considered relatively lower than that of lime and cement. For example, the production of 1 ton of M-GGBS with $M$ at the optimum M:GGBS ratio of 1:9-1:4 only emits about $0.20-0.34$ tons of $\mathrm{CO}_{2}[27,28,37]$. The study by Li et al. [6] also showed that M-GGBS binder protected gypseous soil samples from swelling and contributed to better strength after soaking compared to Portland cement (PC).

The main purpose of this research is the establishment of a new method to stabilize soils subjected to internal sulphate attack by the gypsum $\left(\mathrm{CaSO}_{4}\right)$ by using combined of nano-MgO, MK, and GGBS. For this purpose, different tests (flexural strength (FS), linear expansion (LP) tests, and unconfined compressive strength (UCS)) were performed before and after exposure to water. In this study, two steps have been taken to achieve the objectives. Step 1: running compaction characteristics for each mixture, and step 2: performing UCS, FS, and LP tests before and after sulphate exposure. The samples were cured for 7,28 , and 90 days.

\section{Materials and Methods}

\subsection{Materials}

The materials utilized for this research were kaolin clay $(\mathrm{K})$, hydrated lime $(\mathrm{L})$, calcium sulphate (gypsum) (G), (M), (MK), and (GGBS). Kaolin clay was supplied by KAOLIN (Malaysia) SDN BHD under the brand name MK40 as a white, finely ground, odorless powder. Kaolin clay was used because (i) it is a major component of minerals found in natural clay; (ii) it exhibits a uniform and consistent mineralogy; (iii) it has a low cation exchange capacity [5,40]; (iv) it has a higher alumina content than most other costly minerals and can thus release more alumina when the $\mathrm{pH}$ is high, thereby participating in the formation of ettringite which increases susceptibility to sulphate attack [10,28]. For these reasons, kaolin clay is a suitable control soil in the soil stabilization process. Table 1 summarizes the major properties of kaolin clay. A hydrometer test of clay was conducted according to BS EN ISO 17892-4:2016 [42] with the grading curve shown in Figure 2.

Table 1. Characteristics of the kaolin clay used in this study.

\begin{tabular}{cc}
\hline Properties & Value \\
\hline Liquid limit (\%) & 57.78 \\
Plastic limit (\%) & 38.13 \\
Shrinking limit (\%) & 4.4 \\
Plasticity index & 19.65 \\
Sand (\%) & - \\
Silt (\%) & 88.35 \\
Clay (\%) & 11.65 \\
Electric conductivity $(\mu \mathrm{S} / \mathrm{cm})$ & 320 \\
\hline
\end{tabular}


Table 1. Cont.

\begin{tabular}{cc}
\hline Properties & Value \\
\hline $\mathrm{pH}$ & 5 \\
Specific gravity $\left(\mathrm{G}_{\mathrm{s}}\right)$ & 2.46 \\
Water content $(\%)$ & 1.01 \\
Optimum moisture content $(\%)$ & 29 \\
Maximum dry density $\left(\mathrm{Mg} / \mathrm{m}^{3}\right)$ & 1.326 \\
\hline
\end{tabular}

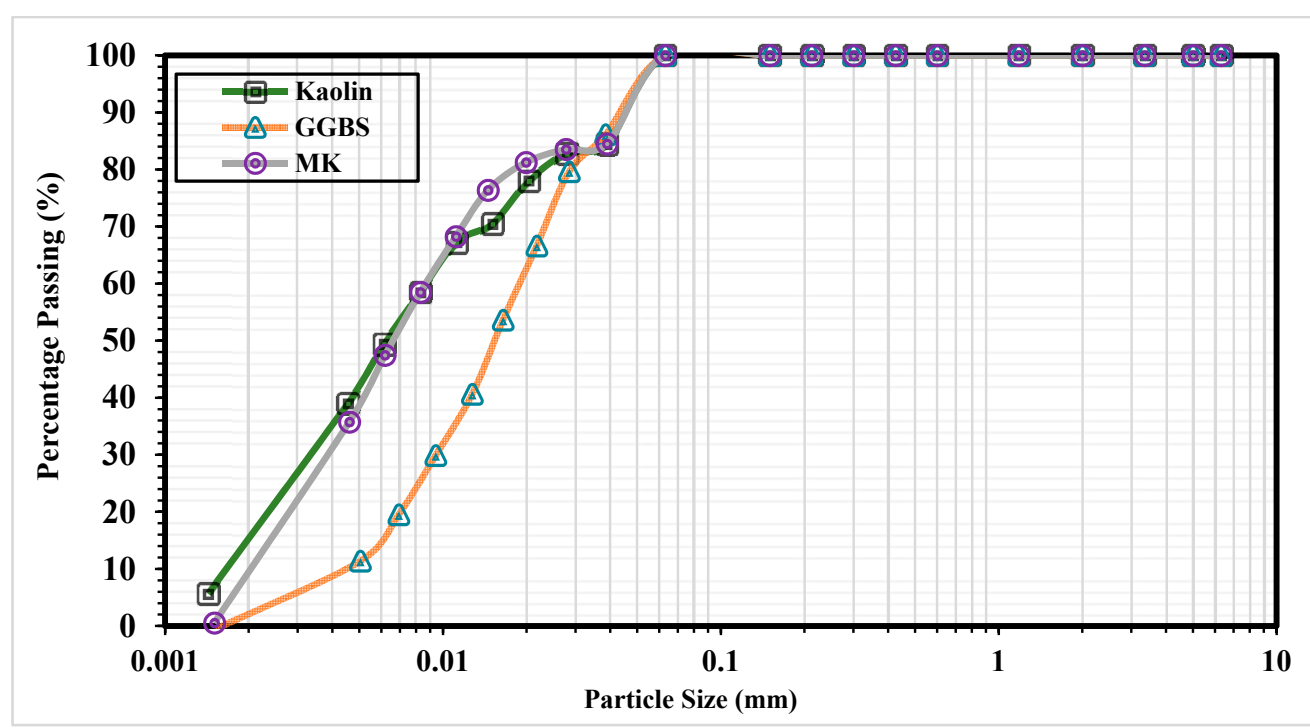

Figure 2. Particle size distribution (PSD) of the kaolin clay, MK, and GGBS used in this study.

L, G, and MK were collected from Sungai Jawi, 14200, Penang, Malaysia. However, $\mathrm{G}\left(\mathrm{CaSO}_{4} \cdot 2 \mathrm{H}_{2} \mathrm{O}\right)$ was selected in this research due to its much lower solubility compared to other sulphate types (potassium sulphate, magnesium sulphate, and sodium sulphate), as presented in Table 2. Moreover, it is one of the sulphates that contain calcium, and it is logical that it would form ettringite if a non-calcium-based stabilizer had been used, as presented in Table 2.

Table 2. Most common types of sulphates found in soil.

\begin{tabular}{cccc}
\hline Sulphate Type & Common Name & Chemical Formula & Solubility \\
\hline Calcium & Selenite, gypsum & $\mathrm{CaSO}_{4} \cdot 2 \mathrm{H}_{2} \mathrm{O}$ & 1.44 \\
Potassium & Arcanite & $\mathrm{K}_{2} \mathrm{SO}_{4}$ & 130 \\
Magnesium & Epsomite & $\mathrm{MgSO}_{4} \cdot 7 \mathrm{H}_{2} \mathrm{O}$ & 225 \\
Sodium & Themadite, mirabilite & $\mathrm{Na}_{2} \mathrm{SO}_{4} \cdot 10 \mathrm{H}_{2} \mathrm{O}$ & $>225$ \\
\hline
\end{tabular}

Metakaolin is produced from kaolin, a natural material. It is a pozzolanic material that results from the heating of kaolin at $700-750{ }^{\circ} \mathrm{C}$; its classification as a pozzolanic material follows the ASTM C 618 standard. MK exhibits a high surface area and amorphous structure which contributes to its high pozzolanic reactivity $[33,43]$. The water content of kaolin is reduced during the heating process, thereby altering its structure and forming metakaolin, an amorphous aluminosilicate $\left(\mathrm{Al}_{2} \mathrm{O}_{3} \cdot 2 \mathrm{SiO}_{2}\right)$ as seen in Equation (1) [44].

$$
\mathrm{Al}_{2} \mathrm{O}_{3} \cdot 2 \mathrm{SiO}_{2} \cdot 2 \mathrm{H}_{2} \mathrm{O} \stackrel{700-750 \text { (heat) }}{\rightarrow} \mathrm{Al}_{2} \mathrm{O}_{3} \cdot 2 \mathrm{SiO}_{2}
$$

GGBS is a waste-product from the pig-iron manufacturing process and is formed through the rapid cooling of molten iron slag to retain its amorphous structure, followed by grinding to increase its specific surface area. The GGBS used in this study was collected 
from MDC Sungai Pentani Company, Malaysia. It was chosen to reduce the rate of ettringite formation through the provision of more $\mathrm{Al}$ and $\mathrm{Si}$, which react with $\mathrm{Ca}^{2+}$ to form complex cementing gels $[10,35,36]$. The denser structure and lower calcium ion content of GGBS should contribute to superior sulphate resistance $[8,28,45]$. A hydrometer test of MK and GGBS with the grading curve is shown in Figure 2.

In this research, $\mathrm{M}$ was chosen, as it is a green and low-carbon clay soil stabilizer. It was collected from Hang Zhou Jiu Peng New Material Co., Ltd., Hangzhou, China as a white, fine, crystalline powder. The production of reactive $\mathrm{M}$ requires low temperatures, consumes less fuel, and emits less $\mathrm{CO}_{2}$ than that of Portland cement (PC) [6,28]. Nanostructured binders have been receiving more attention recently because the main hydrate cement is also a natural nanostructured material $[24,46]$. Furthermore, it reduces sulphate-induced expansion and has higher reactivity and a lower crystallinity $[6,34]$, thereby increasing the rate of reaction with water $[38,47]$.

The chemical content of the materials was determined using X-ray fluorescence test (XRF) as listed in Table 3.

Table 3. Chemical compositions of kaolin clay, L, M, G, GGBS, and MK.

\begin{tabular}{|c|c|c|c|c|c|c|}
\hline \multirow{2}{*}{ Oxides } & \multicolumn{6}{|c|}{ Characteristic (\%) } \\
\hline & Kaolin Clay & $\mathbf{L}$ & $\mathbf{M}$ & G & GGBS & MK \\
\hline $\mathrm{CaO}$ & - & - & - & & 37 & 0.2 \\
\hline $\mathrm{CaOH}_{2}$ & - & 92 & - & & - & - \\
\hline $\mathrm{SiO}_{2}$ & 58 & 2.5 & - & & 32.7 & 52 \\
\hline $\mathrm{Al}_{2} \mathrm{O}_{3}$ & 38 & 0.9 & - & & 15.3 & 36 \\
\hline $\mathrm{Ca}_{2} \mathrm{SO}_{4}$ & - & 0.1 & - & 99 & - & - \\
\hline $\mathrm{SO}_{3}$ & - & - & 0.03 & & 4.7 & - \\
\hline $\mathrm{MgO}$ & - & 3.5 & 99.5 & & 8.1 & 0.1 \\
\hline $\mathrm{Cl}$ & - & - & 0.01 & 0.005 & - & - \\
\hline $\mathrm{Fe}$ & - & 0.06 & 0.01 & 0.005 & - & 8 \\
\hline $\mathrm{H}_{2} \mathrm{O}$ & - & 0.7 & 0.2 & & - & - \\
\hline Loss on ignition & $11-14$ & 0.24 & 0.25 & 0.99 & 2.2 & 3.7 \\
\hline $\mathrm{pH}$ & 5 & 11.85 & 10.83 & 7.5 & 10.23 & 6.71 \\
\hline Specific gravity & 2.46 & 2.23 & 3.58 & 2.34 & 2.96 & 2.33 \\
\hline
\end{tabular}

\subsection{Samples Preparation}

Sulphate-bearing soil or gypseous soil was prepared artificially by mixing kaolin clay with $10 \%$ gypsum (by dry weight of soil). The concentration of sulphate was determined as the worst case according to AASHTO [22,48,49]. The risk of different sulphate levels is summarized in Table 4.

Table 4. Severity of sulphate levels.

\begin{tabular}{ccc}
\hline \multirow{2}{*}{ Risk Level } & \multicolumn{2}{c}{ Sulphate Concentration } \\
\cline { 2 - 3 } & Parts per Million & Percentage of Dry Weight \\
\hline Low risk & $>3000 \mathrm{ppm}$ & $>3 \%$ \\
Moderate risk & $3000-5000 \mathrm{ppm}$ & $3-5 \%$ \\
Moderate to high risk & $5000-8000 \mathrm{ppm}$ & $5-8 \%$ \\
High to unacceptable risk & $>8000 \mathrm{ppm}$ & $>8 \%$ \\
Unacceptable risk & $>10,000 \mathrm{ppm}$ & $>10 \%$ \\
\hline
\end{tabular}

Cylinder samples of $50 \times 100 \mathrm{~mm}$ (diameter $\times$ height) dimension were prepared as reported by $[5,6,50]$ for tests of linear expansion (LP), flexural strength (FS), and unconfined compressive strength (UCS). Each mixture system was compacted with an optimum moisture content (OMC) and maximum dry density (MMD) following the BSEN 13286-2:2010 standard [51], as shown in Table 5. After compaction of samples, each sample was covered using cling film to reduce moisture loss. 
Table 5. Results of compaction test.

\begin{tabular}{|c|c|c|c|c|c|c|}
\hline \multicolumn{3}{|c|}{ Stabilizer } & \multirow{2}{*}{\multicolumn{2}{|c|}{$\begin{array}{c}\text { MDD }\left(\mathrm{Mg} / \mathrm{m}^{3}\right) \\
\text { Dosage }(\%)\end{array}$}} & \multirow{2}{*}{\multicolumn{2}{|c|}{$\begin{array}{c}\text { OMC (\%) } \\
\text { Dosage }(\%)\end{array}$}} \\
\hline \multirow{2}{*}{ Type } & \multicolumn{2}{|c|}{ Binder Ratio (\%) } & & & & \\
\hline & $10 \%$ & $20 \%$ & $10 \%$ & $20 \%$ & $10 \%$ & $20 \%$ \\
\hline K & 0 & 0 & 1.326 & 1.326 & 29 & 29 \\
\hline \multicolumn{7}{|l|}{ Unary } \\
\hline $\mathrm{L}$ & 100 & 100 & 1.28 & 1.27 & 30 & 32 \\
\hline M & 100 & 100 & 1.37 & 1.39 & 29 & 29.5 \\
\hline \multicolumn{7}{|l|}{ Binary } \\
\hline \multirow[t]{3}{*}{ M-MK } & $7.5: 2.5$ & $2.5: 17.2$ & 1.335 & 1.32 & 28 & 29.5 \\
\hline & $5: 5$ & $5: 15$ & 1.33 & 1.31 & 28.5 & 30 \\
\hline & $2.5: 7.5$ & $7.5: 12.5$ & 1.315 & 1.3 & 29.5 & 30.4 \\
\hline \multirow[t]{3}{*}{ M-GGBS } & $7.5: 2.5$ & $2.5: 17.2$ & 1.375 & 1.38 & 27.2 & 26 \\
\hline & $5: 5$ & $5: 15$ & 1.38 & 1.39 & 25 & 24.5 \\
\hline & $2.5: 7.5$ & $7.5: 12.5$ & 1.39 & 1.4 & 24 & 23.5 \\
\hline \multicolumn{7}{|l|}{ Ternary } \\
\hline \multirow[t]{3}{*}{ M-GGBS-MK } & $5: 2.5: 2.5$ & $5: 5: 10$ & 1.35 & 1.36 & 25 & 26 \\
\hline & & 5:10:5 & - & 1.37 & - & 25.5 \\
\hline & & $5: 12.5: 2.5$ & - & 1.38 & - & 25 \\
\hline
\end{tabular}

The total binder contents were fixed at $10 \%$ and $20 \%$ based on the weight of the soil (see Table 6) for each system (unary, binary, and ternary). This was achieved using activator (L) calcium-based stabilizer and (M) non-calcium-based stabilizer at dosages of $10 \%$ and $20 \%$, with (G) calcium sulphate dosed at $10 \%$ (as a worst case) into kaolin clay. The ratios of $\mathrm{M}$ stabilized with (MK and GGBS) (Figure 2 shows a comparison of particle size distribution between MK and GGBS) were set as 1:3, 1:1, and 3:1 in a binary system, and 1:05:05, 1:1:2, 1:2:1, and 1:2.5:0.5 in a ternary system. Figure 3 summarizes the experimental process. In total, 462 cylindrical samples were prepared: 207 for testing UCS, 138 for LP, and 117 for FS.

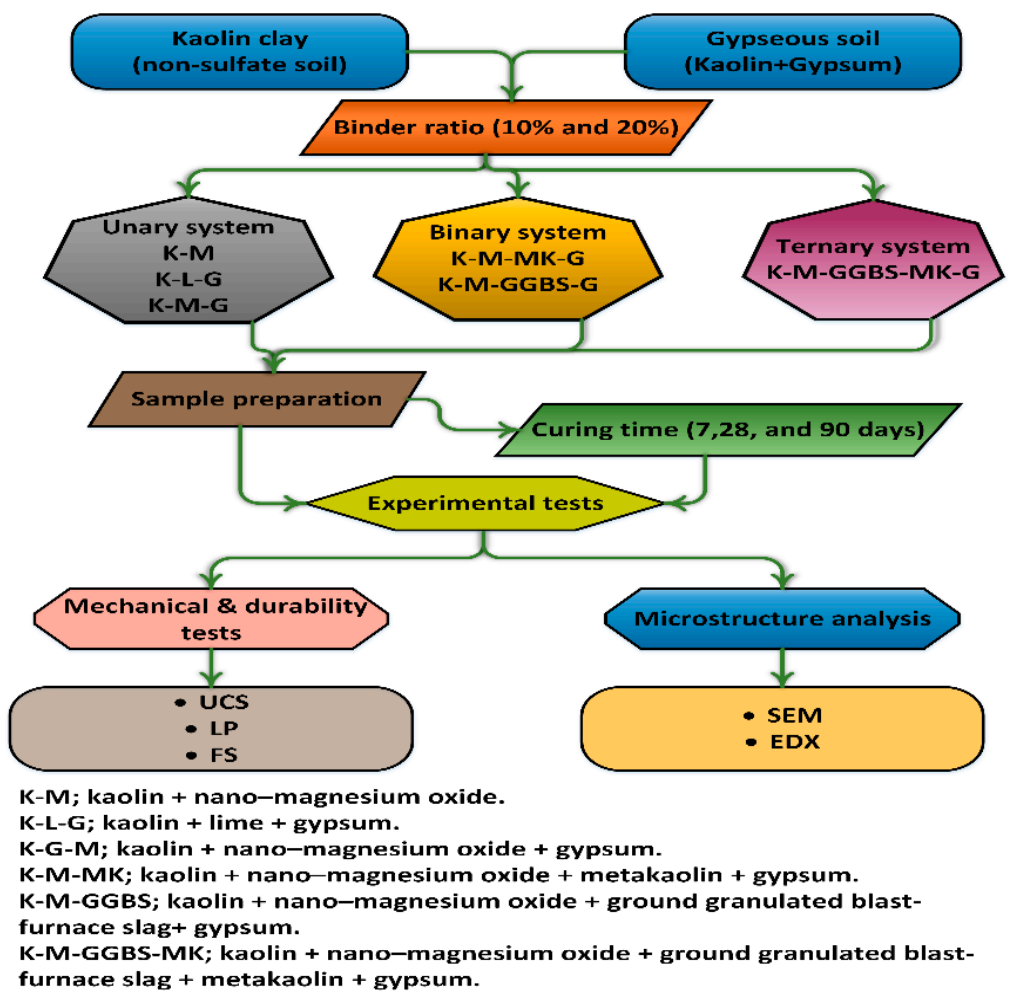

Figure 3. Schematic representation of the experimental procedure. 
Table 6. Mixture designs of stabilizer agents.

\begin{tabular}{cccc}
\hline Mix Code & Binder Composition & Binder Ratio (\%) & Dosage (\%) \\
\hline Unary & K & - & - \\
K & L & 100 & 10,20 \\
K-L & M & 100 & 10,20 \\
K-M & L & 100 & 10,20 \\
K-L-G & M & 100 & 10,20 \\
K-M-G & M:MK & $3: 1,1: 1,1: 3$ & 10,20 \\
Binary & M:GGBS & $3: 1,1: 1,1: 3$ & 10,20 \\
K-M-MK-G & & $1: 0.5: 0.5,1: 1: 2,1: 2: 1,1: 2.5: 0.5$ & 10,20 \\
K-M-GGBS-G & M:GGBS:MK & \\
Ternary & & \\
K-M-GGBS-MK-G
\end{tabular}

(K) Kaolin, (G) Gypsum, (L) hydrated lime, (M) Nano-magnesium oxide, (MK) Metakaolin, (GGBS) Ground granulated blast-furnace slag.

\subsection{Experiments}

\subsubsection{Linear Expansion Test (Swelling) (LP) Test}

Two cylindrical samples were prepared for each mix proportion, and were subjected to curing for 7, 28, and 90 days to establish their vertical swelling ratio (\%). Swelling readings were recorded every $24 \mathrm{~h}$ until no significant swelling ratio was observed after partial soaking in water. The LP test was conducted following the BS EN 13286-49:2004 standard [52].

\subsubsection{Unconfined Compressive Strength (UCS) Test}

The UCS test was performed according to BS EN ISO 17892-7:2018 [53] for each mix proportion; three cylindrical samples were tested for compressive strength before and after soaking. "Before soaking" implies that the samples had been cured for 7, 28, and 90 days without having been immersed in water, while "after soaking" implies after the linear expansion test, which was 52 days after the preparation of the samples for all soil stabilization systems. The samples were subjected to a constant compression strain rate of $1 \mathrm{~mm} / \mathrm{min}$ until failure.

\subsubsection{Flexural Strength (FS) Test}

For this test, specimens were prepared as for the UCS and LP tests. A three-point bending test was used to determine the FS for kaolin clay and the optimum mixing of sulphate-bearing soil mixed with the calcium-based and non-calcium-based stabilizers. For each test, three samples were prepared using a compaction mould at the optimum moisture content $(\mathrm{OMC})$ and maximum dry density (MMD); the curing process was done for 7, 28, and 90 days. The ASTM D1635 was followed during the flexural strength test; the test was performed at a constant strain rate of $0.1 \mathrm{~mm} / \mathrm{min}$. Equation (2) was used to calculate the flexural stress for the outer layer of each cylindrical specimen.

$$
\mathrm{FS}=\mathrm{PL} / \pi \mathrm{r}^{3}
$$

where FS = flexural strength; $\mathrm{P}=$ maximum load applied; $\mathrm{r}$ = sample radius; $\mathrm{L}=$ support span.

\subsubsection{Microstructure Analysis (SEM/EDX)}

The samples were subjected to surface morphology analysis using scanning electron microscopy (SEM); the elemental content of the samples was also elucidated using energy dispersive spectroscopy (EDS). Small portions of soil specimens were collected from carefully hand-broken samples after UCS and then dried for $24 \mathrm{~h}$ at $105^{\circ} \mathrm{C}$ prior to testing. 


\section{Results and Discussion}

\subsection{Unconfined Compressive Strength (UCS) Test}

\subsubsection{Effects of M-MK on UCS}

Figures 4 and 5 depict the effects of $\mathrm{L}$ and M additions on the UCS values after 7, 28, and 90 days of curing for the gypseous soil samples. The UCS values for M-treated samples increased from 885.33 to $1108.67 \mathrm{kPa}$ when the M content was increased from $10 \%$ to $20 \%$ without the presence of sulphate at 90 days of curing. Samples treated with L and M (10\% and $20 \%$ ) showed a decrease in UCS values in the presence of sulphate (see Figures 4 and 5). Furthermore, after soaking, the UCS values deteriorated from 885.33 to $635 \mathrm{kPa}$ for M10\%, (reducing by $28.27 \%$ ) and 1108.67 to $1035.33 \mathrm{kPa}$ with $20 \% \mathrm{M}$ content in the presence of sulphate (reducing by $6.62 \%$ ). However, this deterioration, as compared to that of the lime stabilizer, was much less. The observed deterioration in the UCS results can be attributed to ettringite production, the growth of which between the particles of the sample soil would lead to the destruction of the soil structure. In addition, the residual sulphate chelates formed calcium in CSH through a decalcification process, which accounted for the lower strengths of the soaked and unsoaked samples. However, the higher strength of the Mtreated samples might have been due to the hydration process and formation of pozzolanic products that might have improved the strength of the bonds between the soil particles.

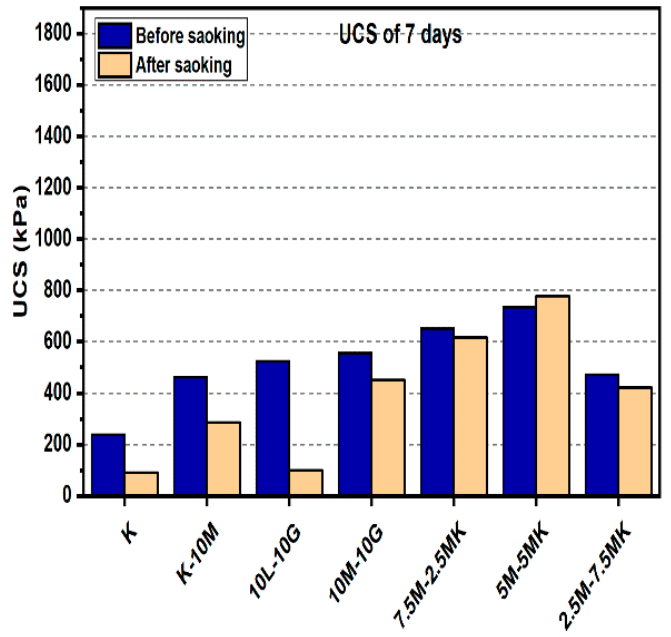

(a)

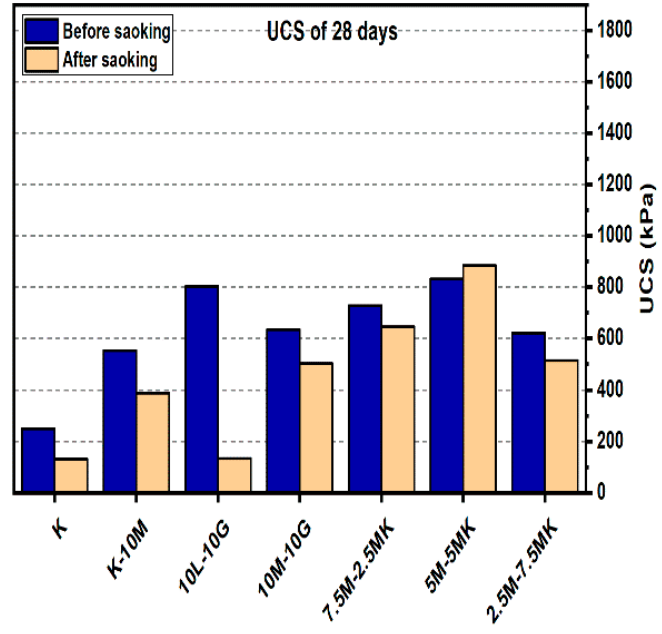

(b)

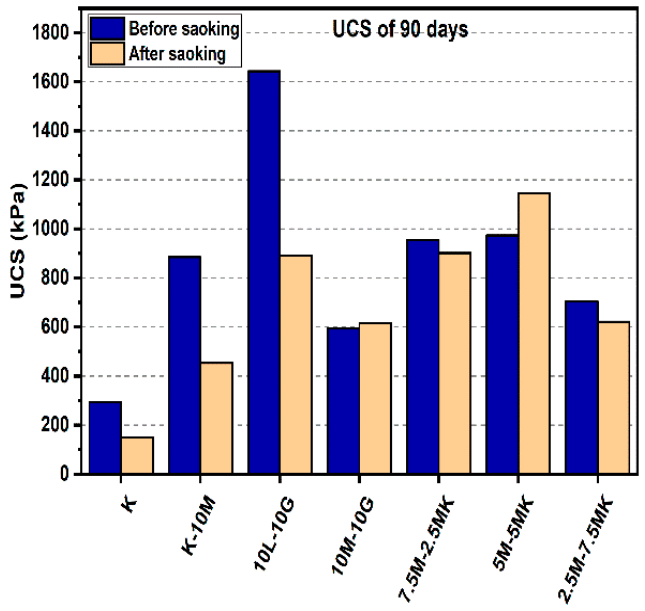

(c)

Figure 4. UCS of soils stabilized with $10 \%$ of $\mathrm{L}, \mathrm{M}$, and M-MK before and after soaking in the presence of sulphate: (a) after curing for 7 days, (b) after curing for 28 days, (c) after curing for 90 days. 


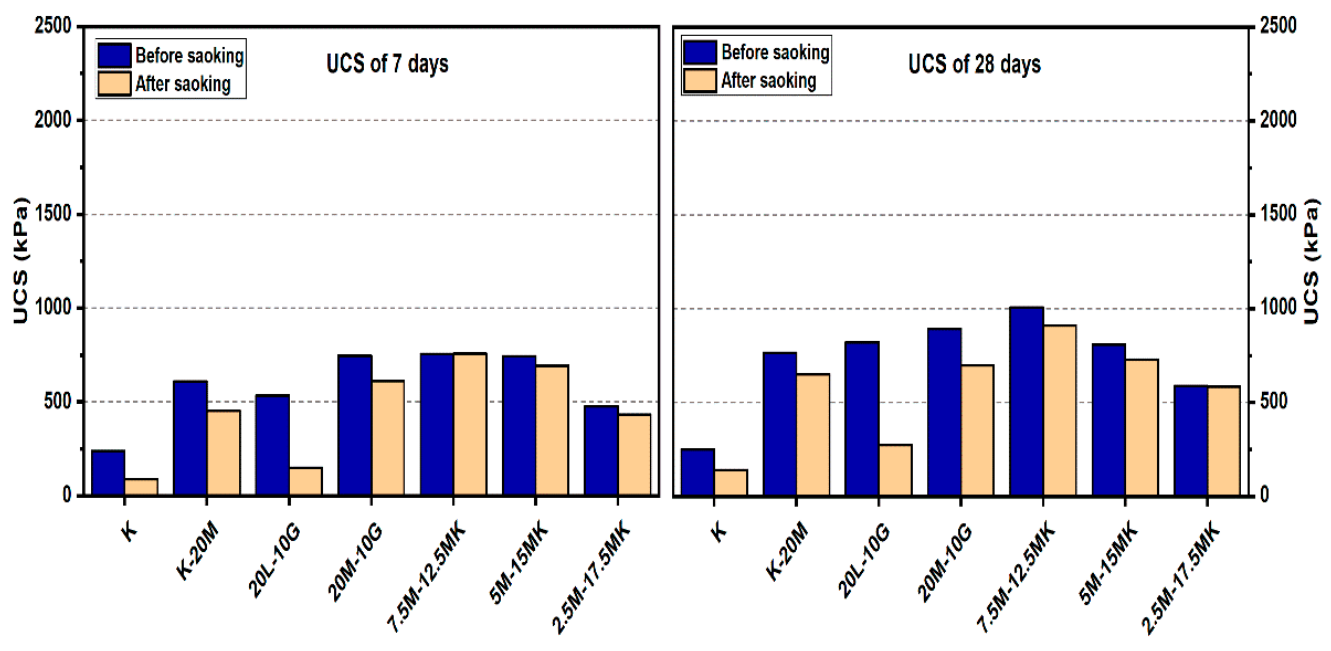

(a)

(b)

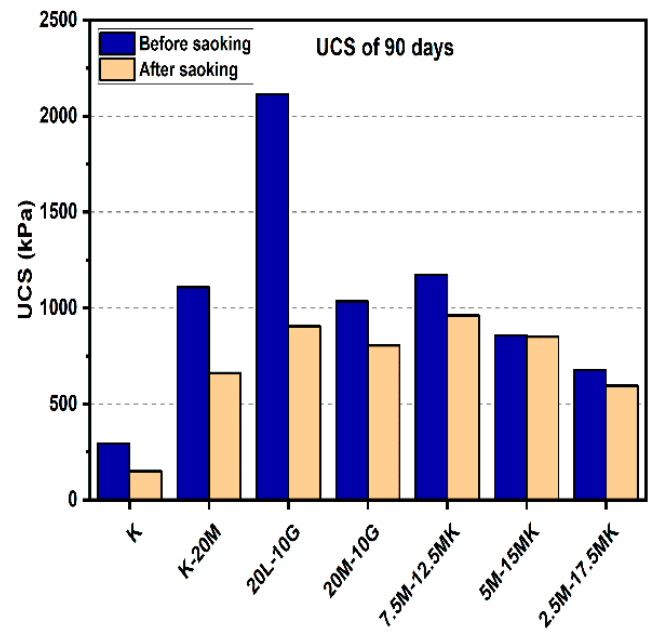

(c)

Figure 5. UCS of soils stabilized with $20 \%$ of L, M, and M-MK before and after soaking in the presence of sulphate: (a) after curing for 7 days, (b) after curing for 28 days, (c) after curing for 90 days.

Figures 4 and 5 show the effects of the MK content on enhancing the USC values for the M-treated samples before soaked after 7, 28, and 90 days of curing in the presence of sulphate. For example, Figure 5 indicates that the sample's UCS values of the samples treated with $7.5 \mathrm{M}-12.5 \mathrm{MK}$ at the age of 90 days increased from $756.33 \mathrm{kPa}$ to $1172.67 \mathrm{kPa}$ as compared to samples at the age of 7 days, where UCS increased by $55.05 \%$. This impact was also observed for 5M-15MK (increased from 591 to $858.33 \mathrm{kPa}$ ), which was improved by $45.23 \%$, and 5M-5MK (increased from 736 to $973 \mathrm{kPa}$ ), which was enhanced by $32.2 \%$. These improvements could be due to pozzolanic product ( $\mathrm{CSH}$ ) formation, which would have improved the USC value for the samples with higher M-MK content. However, all values of UCS decreased after soaking, except soil samples treated with binder $10 \%$ (5M-5MK), increased from $973 \mathrm{kPa}$ to $1145 \mathrm{kPa}$ at the age of 90 days, where improved by 17.68\%. The enhancement of the hydration process could explain this result after immersing in water. A possible reason for the loss in strength of the M-MK stabilized soil after soaking in water, such as $7.5 \mathrm{M}-12.5 \mathrm{MK}$, is the increase of metakaolin content, leading to reduce in hydrotalcite formed. This phenomenon led to cracks during water immersion, resulting in a compromised microstructure of the M-MK stabilized soil and becoming relatively brittle. These results agree with the report by [54], where hydrotalcite formation positively contributed to the greater mechanical property of the binder. 


\subsubsection{Effects of M-GGBS on UCS}

For the M-GGBS stabilizer, all specimens showed enhancement of their UCS values. Figures 6 and 7 presented the maximum UCS of the M-GGBS-stabilized soils at the M:GGBS ratio of $1: 3$ when a $20 \%$ binder was used to stabilize the sulphate-bearing soil: the UCS values were $3327.33,7125$, and $12,115 \mathrm{kPa}$ after curing for 7,28 , and 90 days, respectively. This improvement may have been because of the high content of highly reactive $M$, and because an excessive residual can negatively impact the strength of stabilized soils. Nevertheless, the UCS values of the stabilized samples before and after soaking indicated enhancement in the mechanical performance of the samples after wetting, except ratios of 3:1 and 1:1 when used to treat gypseous soil samples with 10\% M-GGBS-stabilizer (see Figure 6); for example, the samples treated with 5M-5GGBS deteriorated by $13.02 \%, 33.11 \%$ and $29.76 \%$ at 7,28 and 90 days of curing, respectively. The UCS of the treated soil sample with 2.5M:17.5GGBS was 11,275 $\mathrm{kPa}$ after soaking, which was significantly higher than that before soaking $(914.23 \%)$ after 7 days of curing. After soaking, the 5M-15GGBS ratio of 1:3 exhibited an optimum UCS value of $12,831 \mathrm{kPa}$, which was increased by $5.91 \%$ after 90 days of curing. However, the UCS values showed a decline at higher M-GGBS ratios. These findings agree with the report by [6], where highly reactive $M$ was found to have better activation efficiency with GGBS compared to low-reactive M; therefore, lower M-GGBS ratios are recommended to achieve higher UCS values.

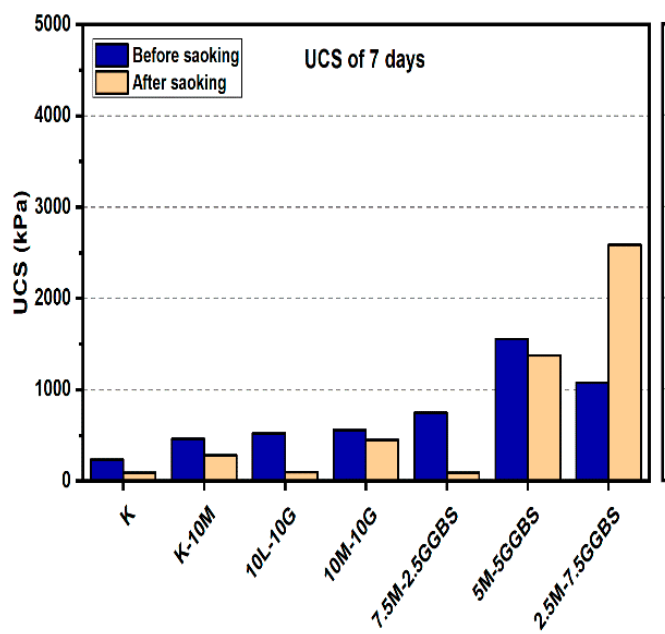

(a)

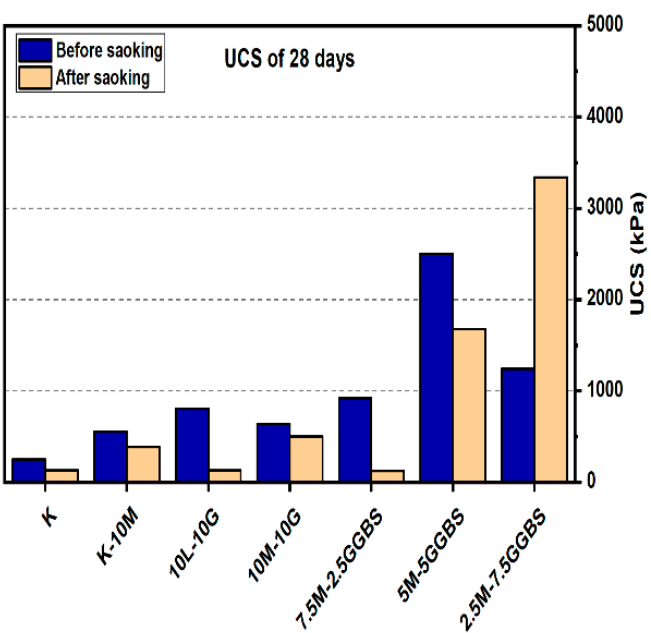

(b)

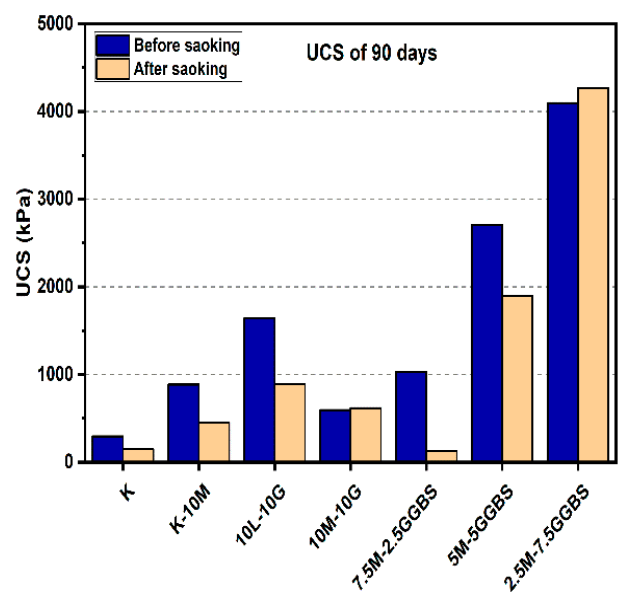

(c)

Figure 6. UCS of soils stabilized with $10 \%$ of L, M, and M-GGBS before and after soaking in the presence of sulphate: (a) after curing for 7 days, (b) after curing for 28 days, (c) after curing for 90 days. 


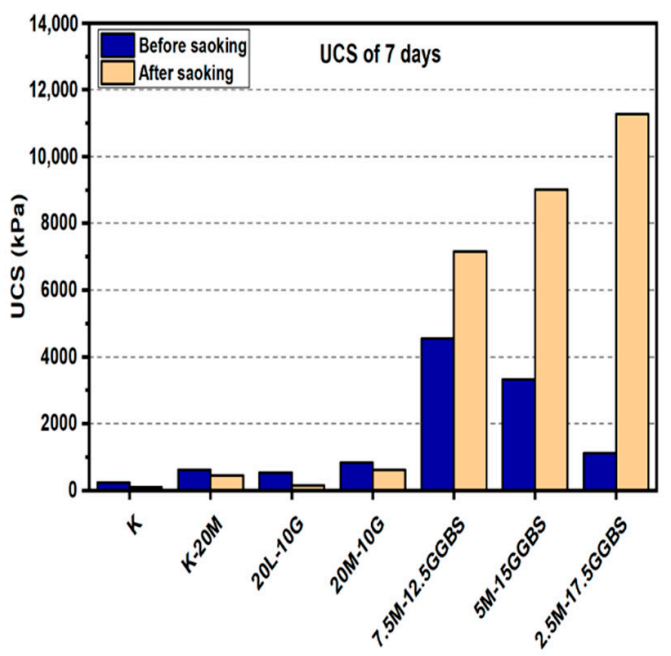

(a)

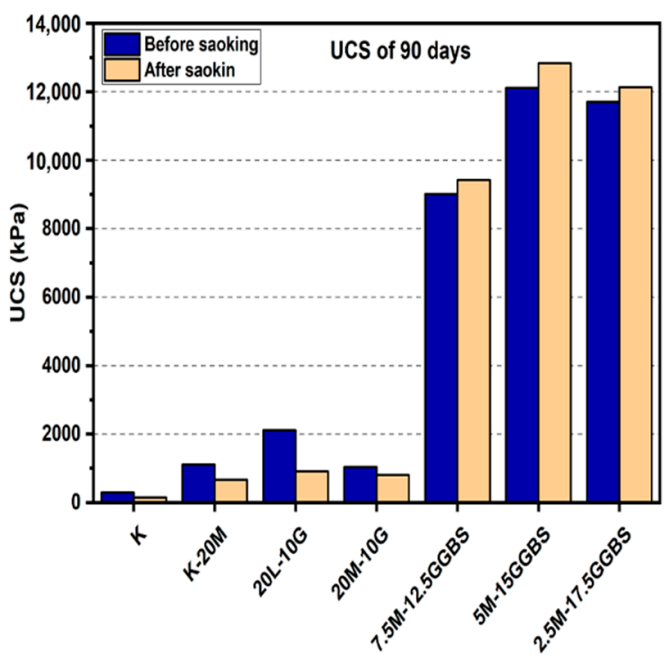

(c)

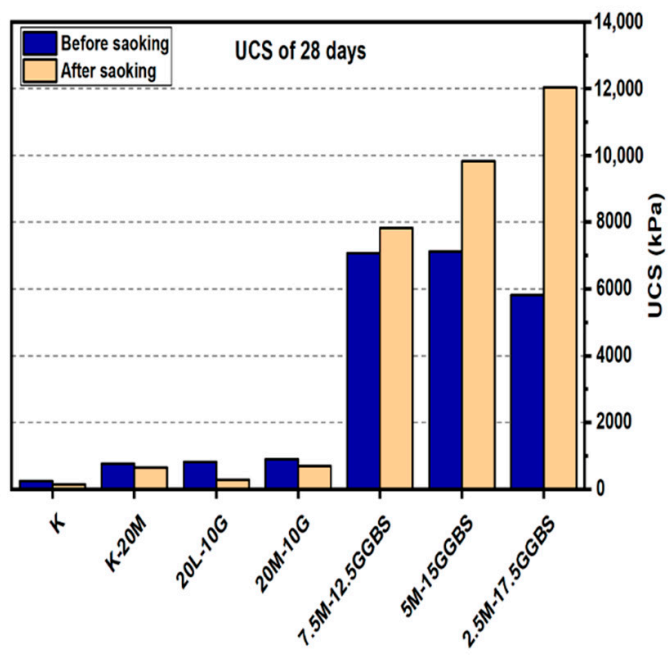

(b)

Figure 7. UCS of soils stabilized with $20 \%$ of L, M, and M-GGBS before and after soaking in the presence of sulphate: (a) after curing for 7 days, (b) after curing for 28 days, (c) after curing for 90 days.

\subsubsection{Effects of M-GGBS-MK on UCS}

Figures 8 and 9 show that all ternary binder compositions improved the UCS values in the stabilized gypseous soil. The highest values of UCS obtained by the M-GGBS-MK stabilizer ratio of 5:12.5:0.5 were $1770.33,3196$, and $4007.33 \mathrm{kPa}$ at the ages of 7,28 , and 90 days, respectively (see Figure 9). However, the lowest enhancements after 7, 28, and 90 days of curing were 581,734, and $994 \mathrm{kPa}$, respectively, when a stabilizer-binder ratio of 5:2.5:2.5 was used (see Figure 8). The UCS decreased with the reduction in the GGBS ratio. 


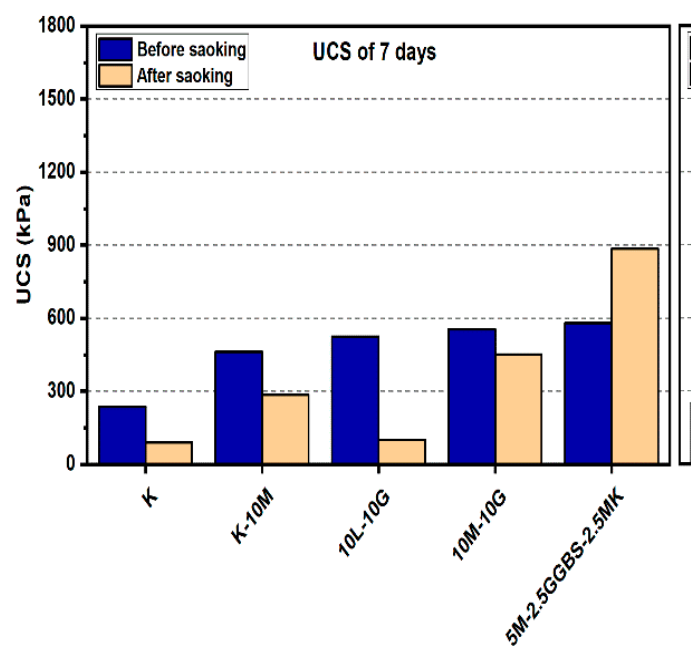

(a)

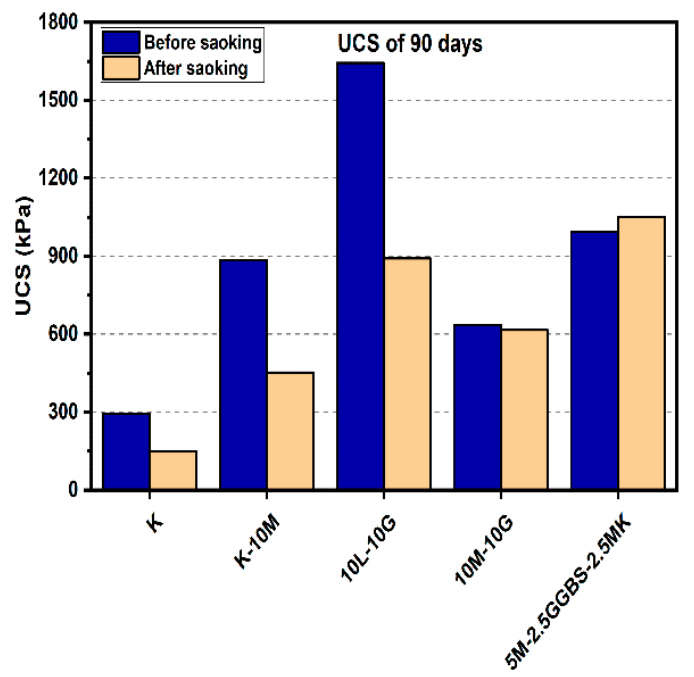

(c)

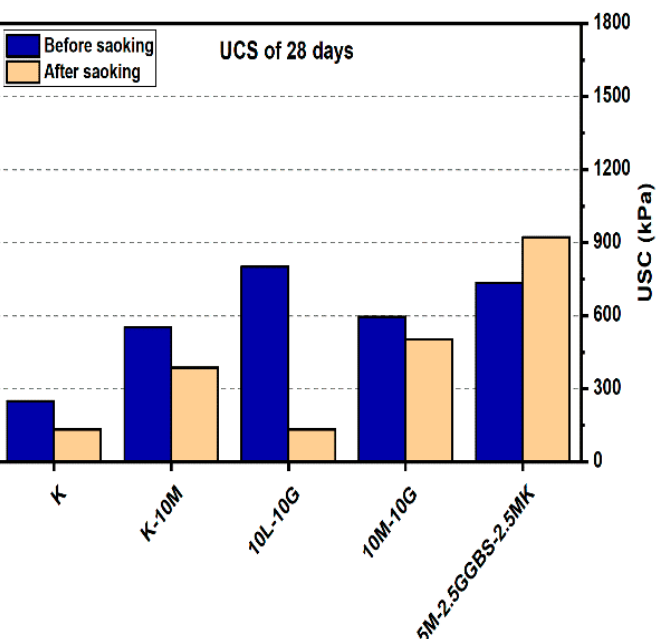

(b)

Figure 8. UCS of soils stabilized with $10 \%$ of L, M, and M-GGBS-MK before and after soaking in the presence of sulphate: (a) after curing for 7 days, (b) after curing for 28 days, (c) after curing for 90 days.

After soaking, the M-GGBS-MK ratio of 5:2.5:2.5 improved the UCS values among all the M-GGBS-MK-stabilized soils, an increase of $52.49 \%, 25.47 \%$, and $5.63 \%$ at the ages of 7 , 28 , and 90 days (see Figure 8). This enhancement in the UCS values might have been due to the hydration process following the prolonging of the curing time from 7 days to 90 days; this should ensure proper hydration, improved strength, and resistance against sulphate attacks [8]. Furthermore, the production of more cementitious gels, such as Calcium silicate hydrates $(\mathrm{CSH})$, calcium aluminate hydrates $(\mathrm{CAH})$, and calcium aluminosilicate hydrates $(\mathrm{CSAH})$, contributed to the consumption of the available calcium, leading to the inhibition of ettringite formation [5]. 


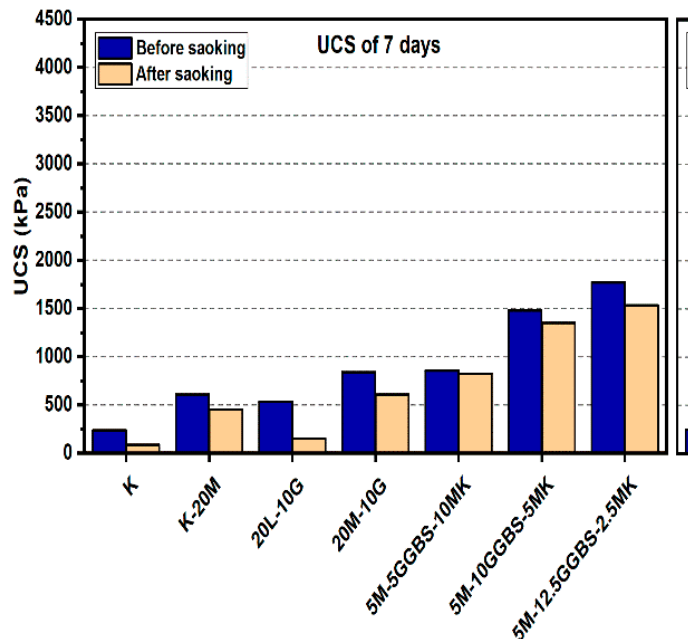

(a)

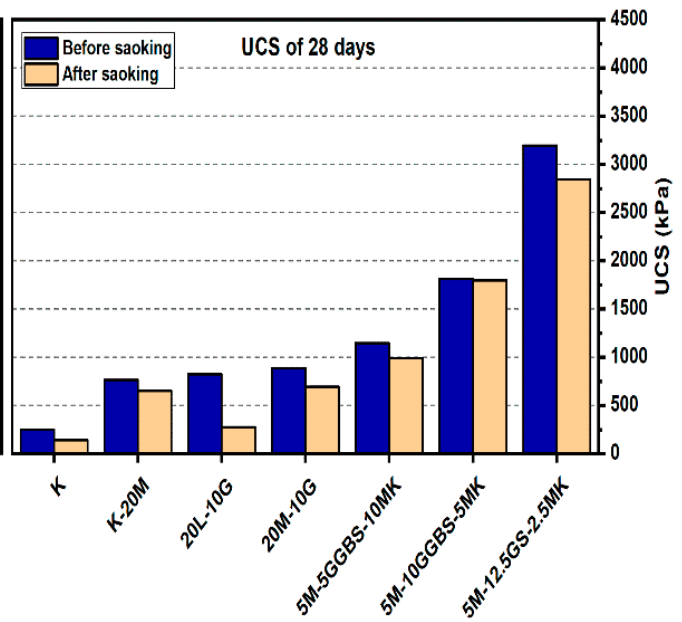

(b)

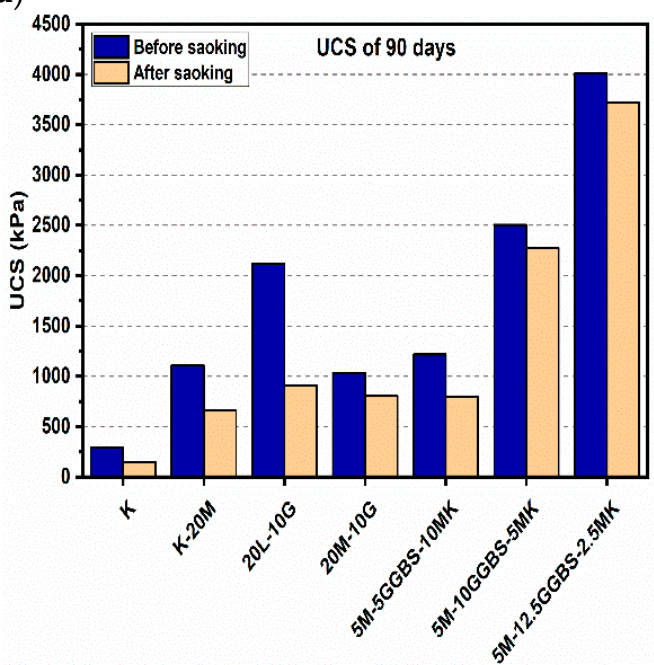

(c)

Figure 9. UCS of soils stabilized with $20 \%$ of L, M and M-GGBS-MK before and after soaking in the presence of sulphate: (a) after curing for 7 days, (b) after curing for 28 days, (c) after curing for 90 days.

\subsection{Linear Expansion Test (Swelling) (LP) Test}

Figures 10-15 illustrate the typical swelling plots for K-M clay and K-L-G and K-M-G clay systems dosed with $10 \%$ wt of gypsum and stabilizer with $10 \%$ and $20 \%$ wt of $\mathrm{L}$ and $\mathrm{M}$ for observatory periods of 7, 28, and 90 days, respectively. Swelling was observed immediately after soaking the cylinder samples in water, which was sustained throughout monitoring until the cessation of swelling. A higher rate of swelling was observed compared to the reported expansion in lime-stabilized sulphate-bearing soils $[5,12,34]$.

Figures 10 and 13 show the highest degree of swelling obtained with a calcium-based stabilizer (10\% wt): Which was $25.226 \%$ with $10 \%$ lime after 7 days curing; meanwhile, the lowest swelling was observed with $20 \%$ lime: $18.313 \%$ after seven days of curing. Nevertheless, the comparison of the swelling values of the treated soils between the calcium-based stabilizer and non-calcium-based stabilizer clearly showed that the noncalcium-based stabilizer $(\mathrm{M})$ had a significant effect on restricting the swelling values. For example, when $10 \%$ and $20 \% \mathrm{M}$ were used, the swelling values were $0.18 \%$ and $0.466 \%$; hence, the swelling was restricted to $99.28 \%$ and $97.45 \%$. This result was due to the absence of calcium in non-calcium-based stabilizer (M), which led to the suppression of ettringite formation. 


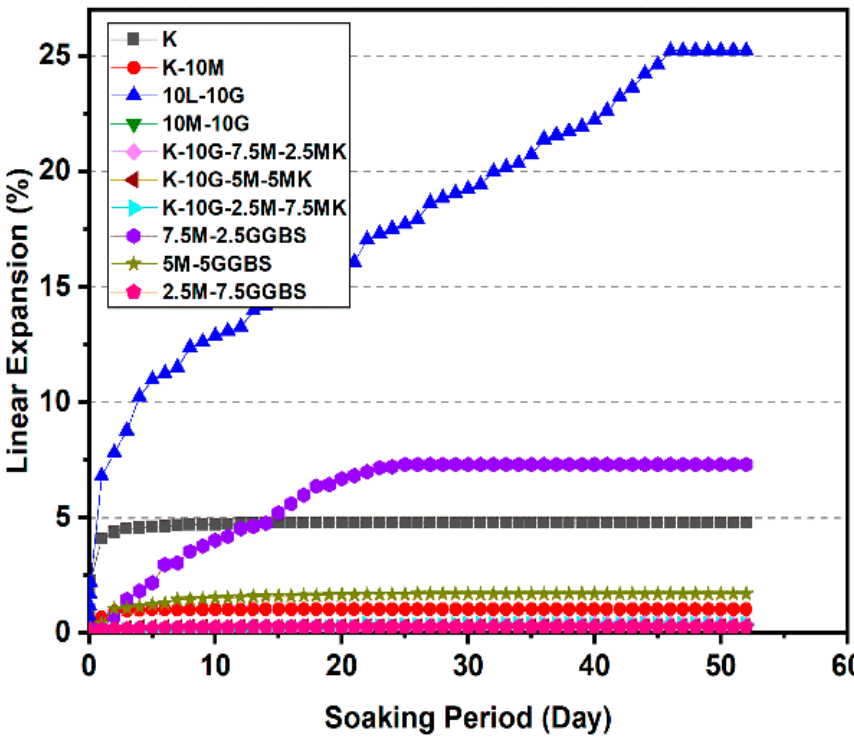

(a)

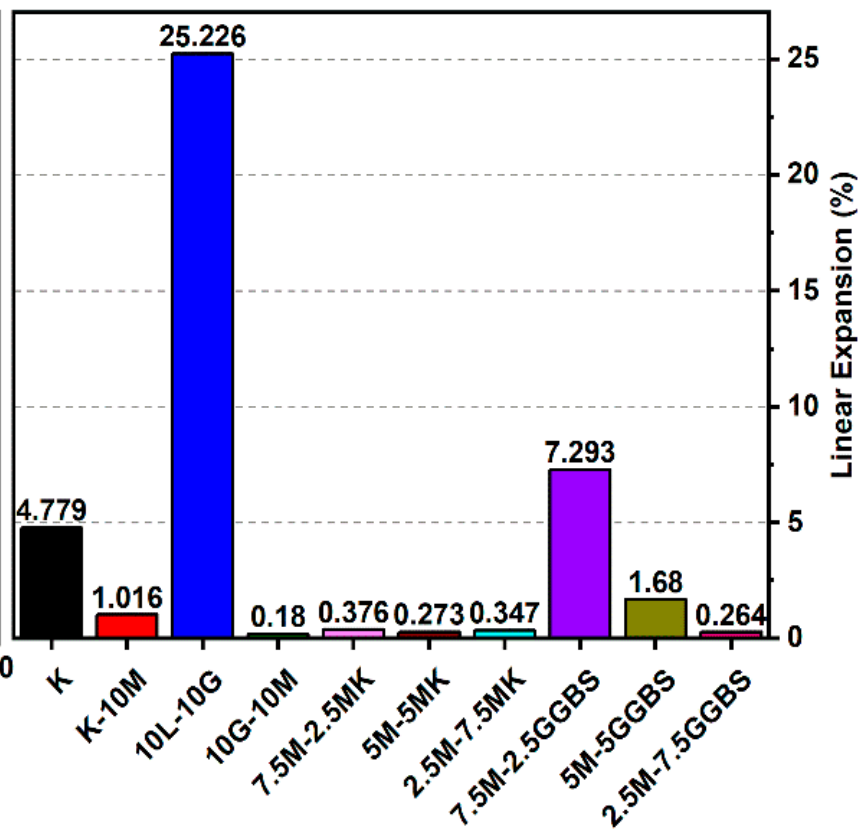

(b)

Figure 10. Vertical swelling strain of soils stabilized with $10 \%$ of L, M, M-MK, and M-GGBS after 7 days of curing: (a) results presented as a line curve, $(\mathbf{b})$ results presented as columns.

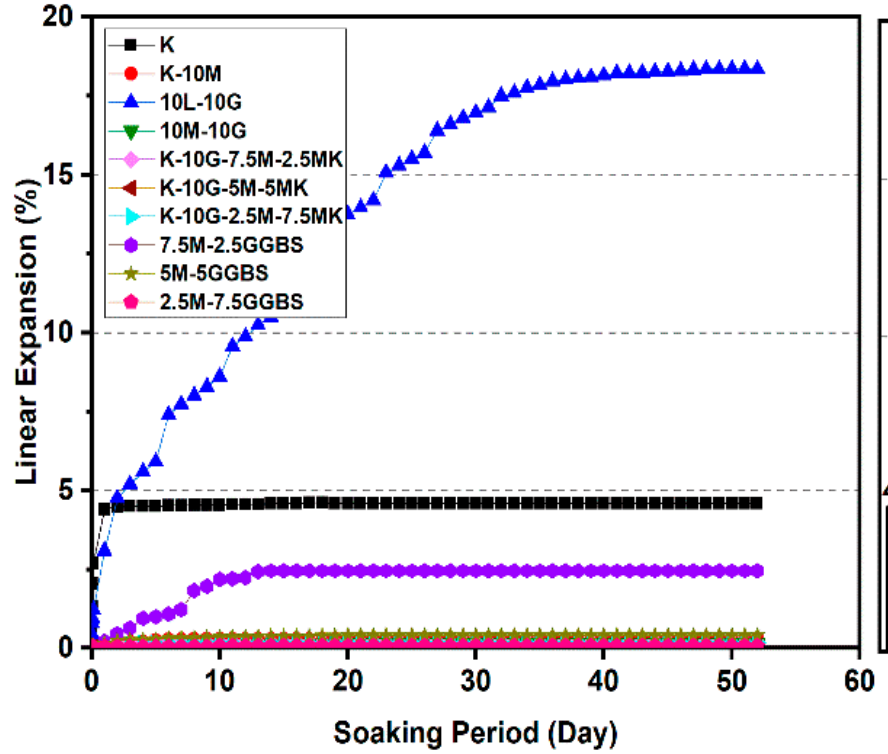

(a)

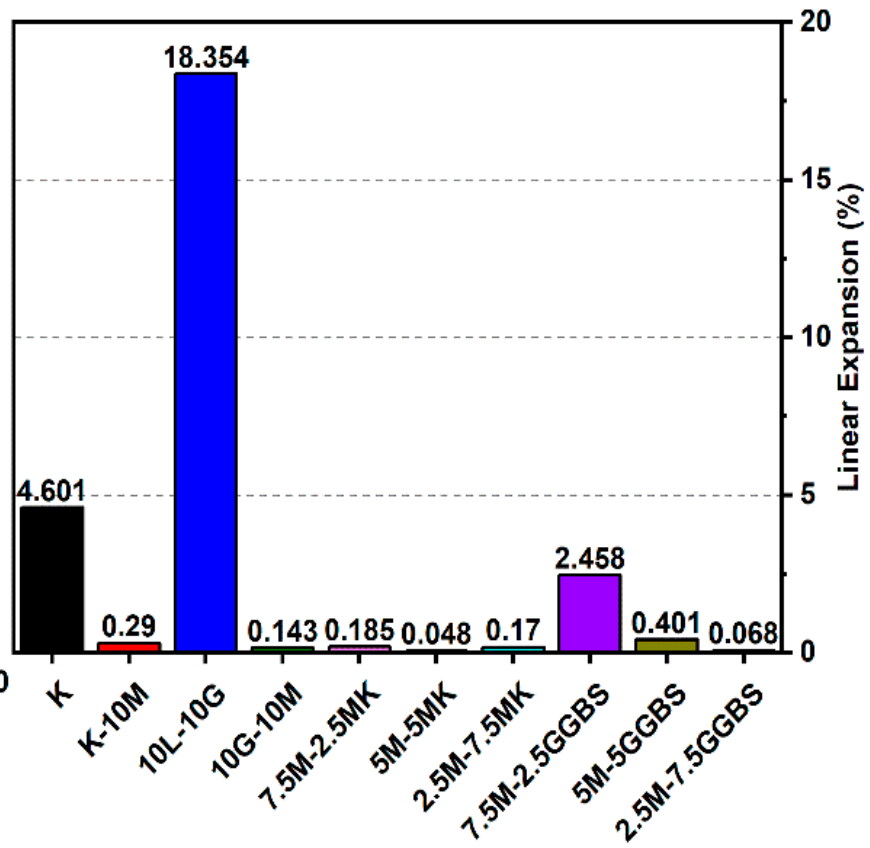

(b)

Figure 11. Vertical swelling strain of soils stabilized with $10 \%$ of L, M, M-MK, and M-GGBS after 28 days of curing: (a) results presented as a line curve, (b) results presented as columns. 


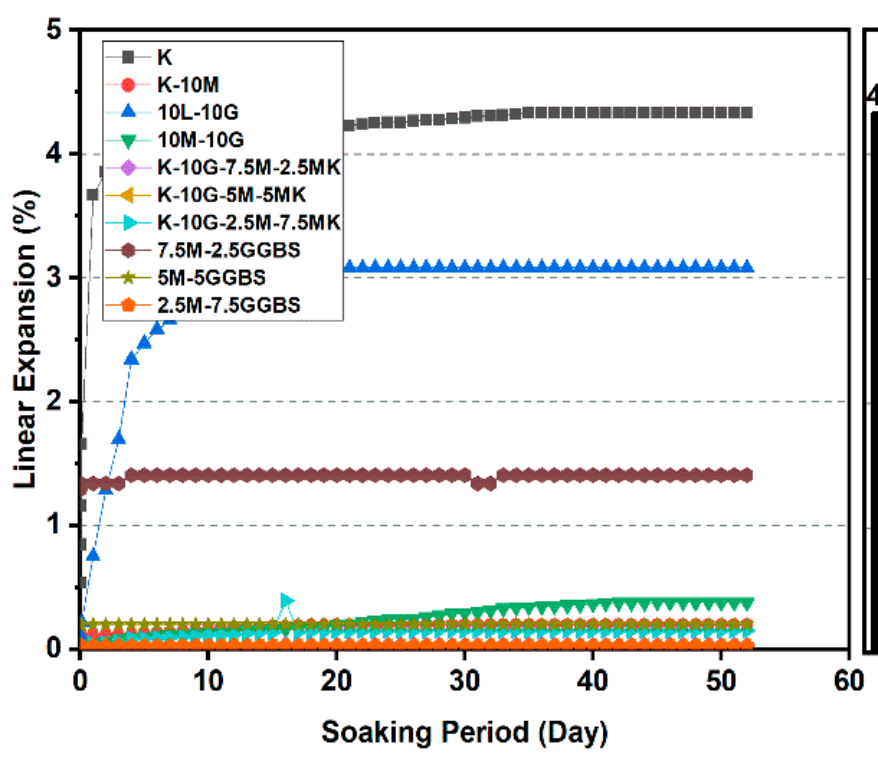

(a)

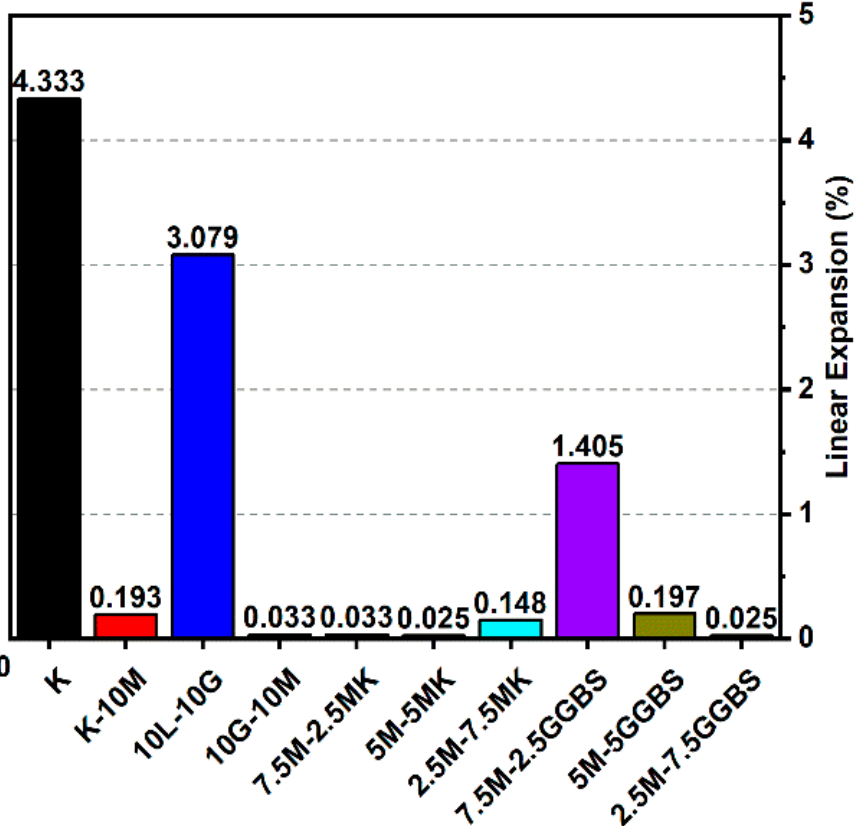

(b)

Figure 12. Vertical swelling strain of soils stabilized with $10 \%$ of L, M, M-MK, and M-GGBS after 90 days of curing: (a) results presented as a line curve, (b) results presented as columns.

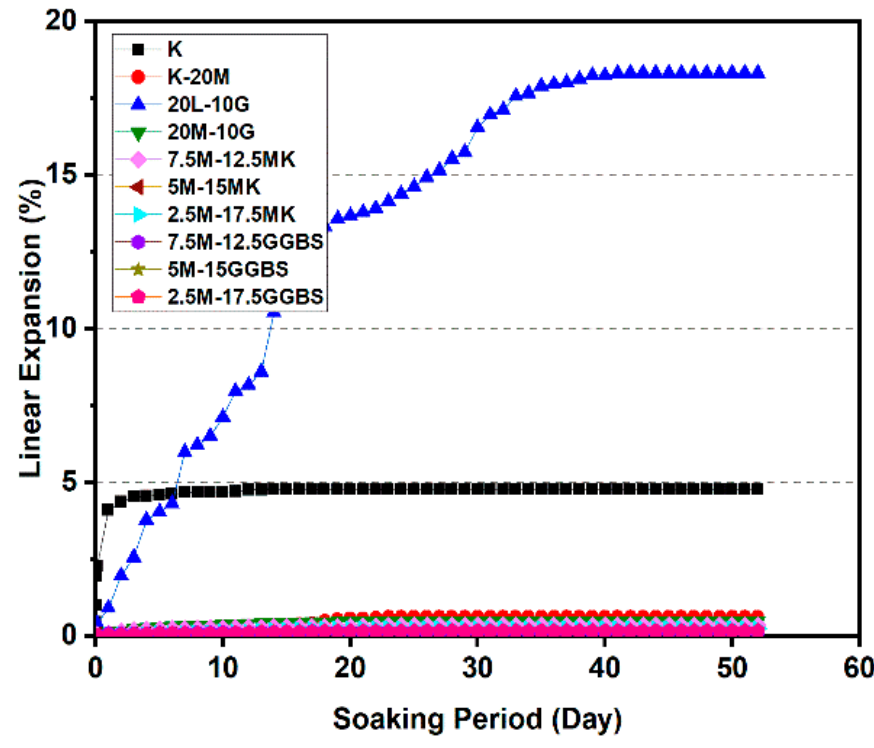

(a)

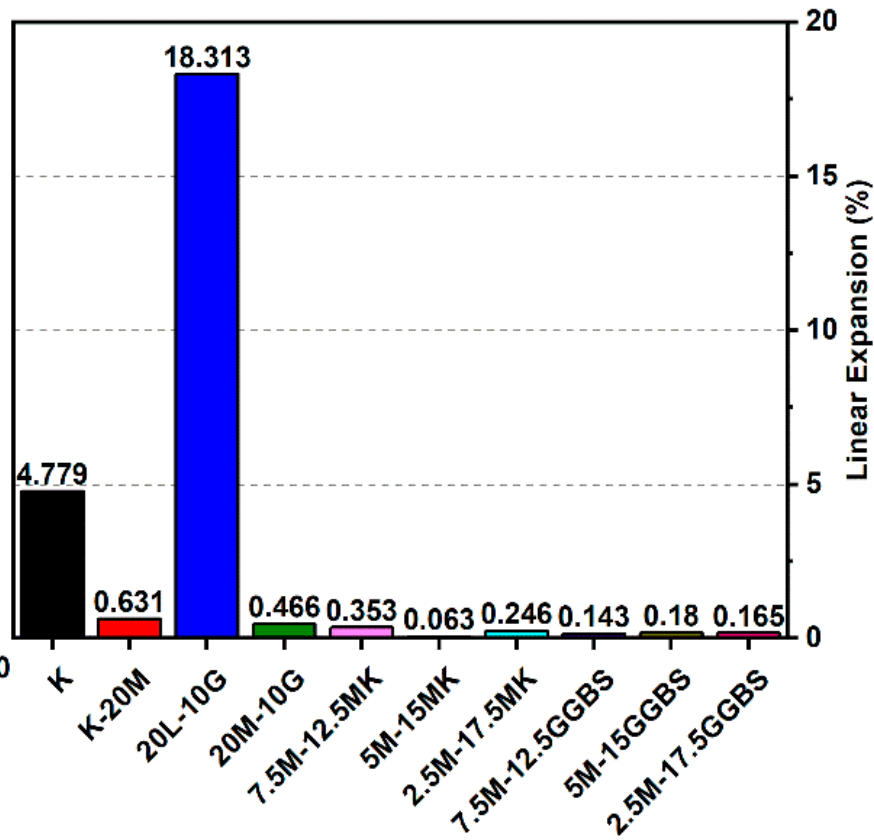

(b)

Figure 13. Vertical swelling strain of soils stabilized with $20 \%$ of L, M, M-MK, and M-GGBS after 7 days of curing: (a) results presented as a line curve, (b) results presented as columns. 


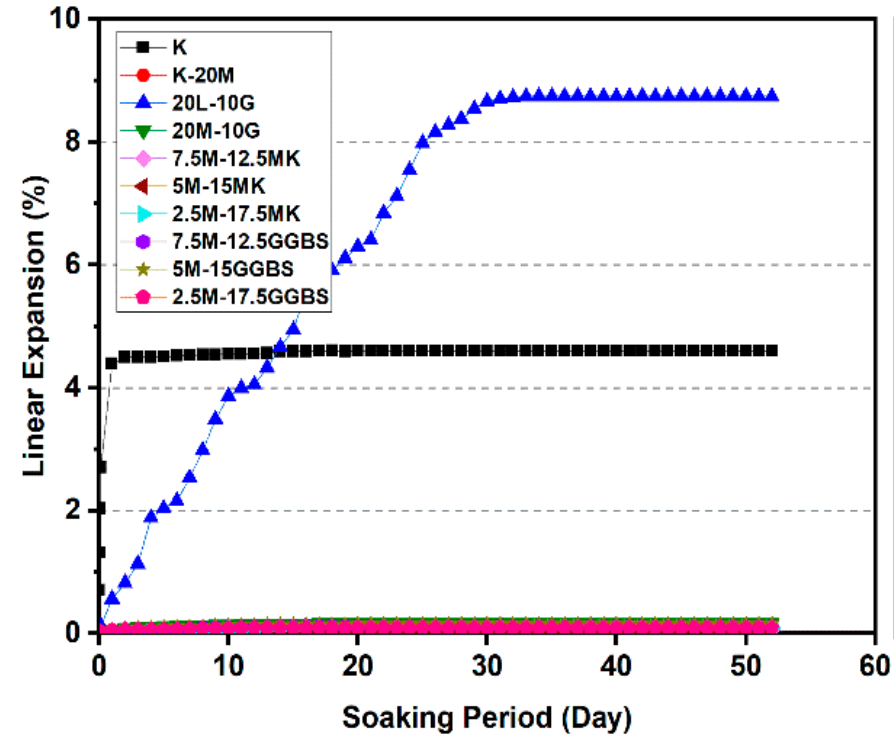

(a)

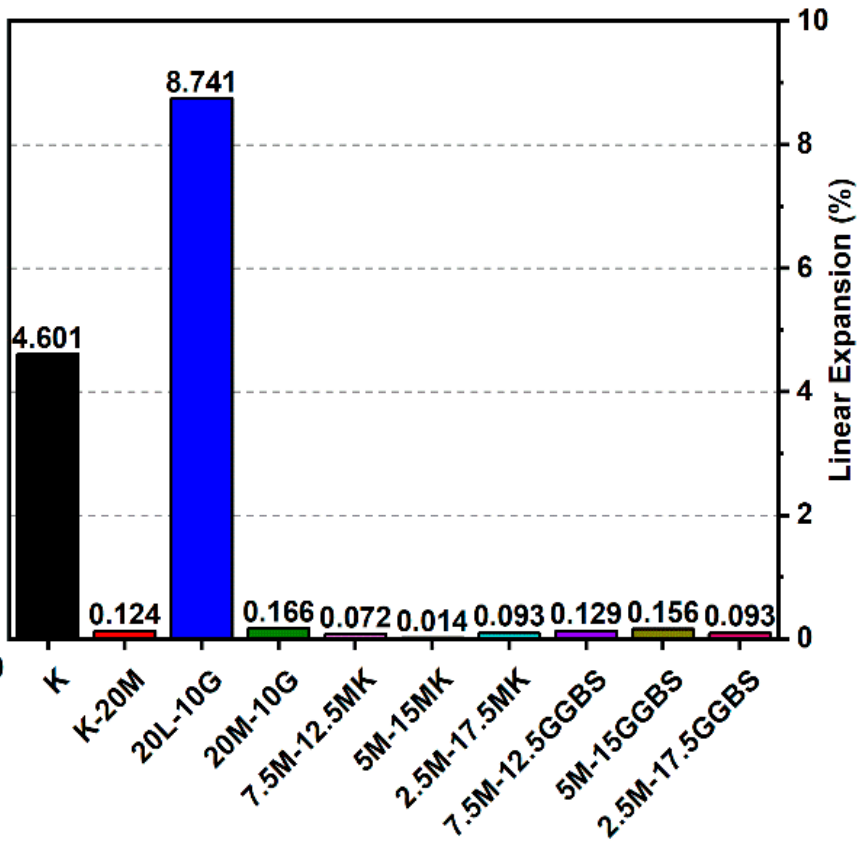

(b)

Figure 14. Vertical swelling strain of soils stabilized with $20 \%$ of L, M, M-MK, and M-GGBS after 28 days of curing: (a) results presented as a line curve, (b) results presented as columns.

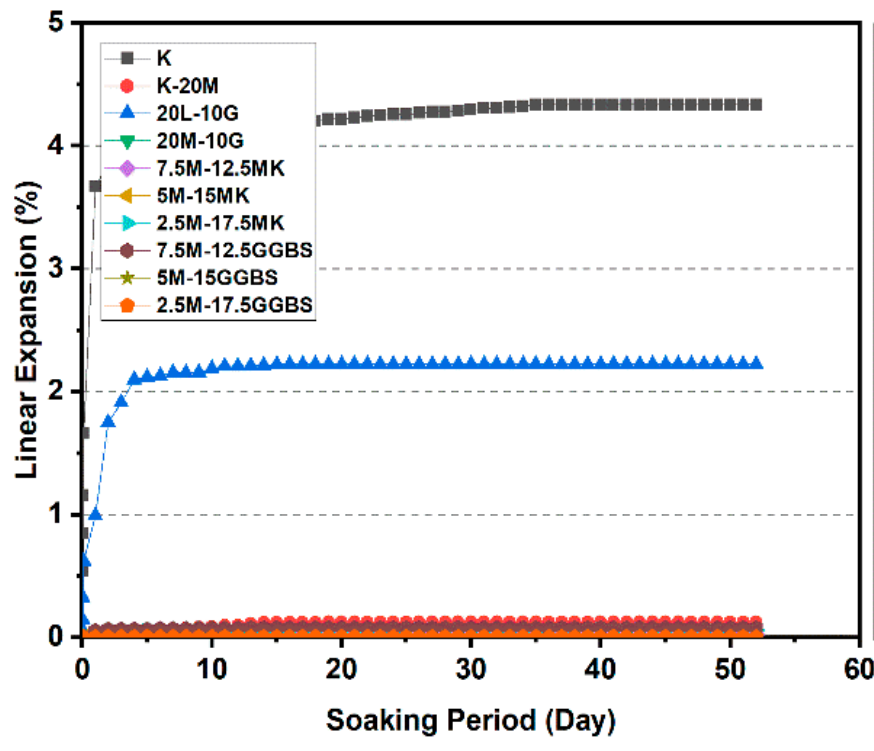

(a)

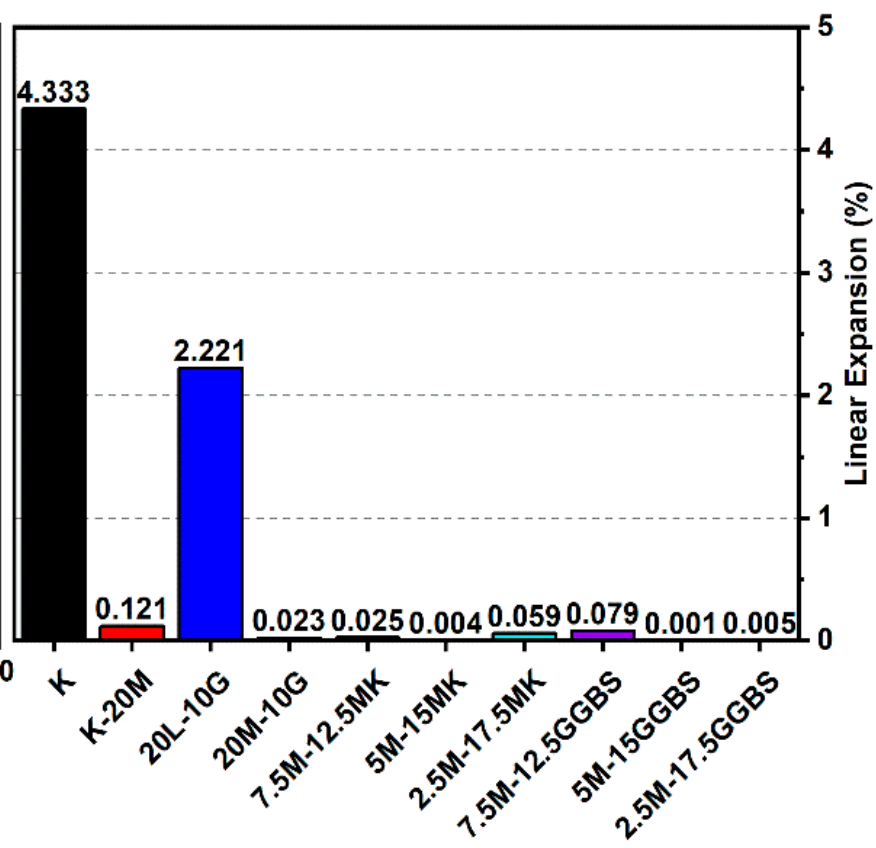

(b)

Figure 15. Vertical swelling strain of soils stabilized with $20 \%$ of L, M, M-MK, and M-GGBS after 90 days of curing: (a) results presented as a line curve, (b) results presented as columns.

\subsubsection{Effects of M-MK on Swelling}

Utilizing the M-MK stabilizer resulted in a restriction in the volume change (swelling) for all gypseous soil specimens, as presented in Figures 10-15. The lowest minimum values of swelling, achieved with a $5 \mathrm{M}-5 \mathrm{MK}$ ratio of $1: 1$, were $1.68 \%, 0.401 \%$, and $0.197 \%$ after 7 , 
28 , and 90 days of curing, respectively, with the swelling inhibited $93.34 \%, 97.82 \%$, and $93.61 \%$, respectively, as compared to $10 \%$ K-L-G. Furthermore, the $20 \%$ M-MK-stabilizer led to a low volumetric change after 90 days of curing at $0.025 \%, 0.004 \%$, and $0.059 \%$, with the swelling suppressed to $98.87 \%, 99.82 \%$, and $97.34 \%$, respectively, as compared to $20 \%$ K-L-G. This reduction in swelling can be attributed to the restriction of ettringite formation and the production of more CSH compounds in the absence of calcium.

\subsubsection{Effects of M-GGBS on Swelling}

Figures 10-15 present the vertical volume change (swelling) of gypseous soil treated with the M-GGBS stabilizer. The maximum vertical volume change was $7.293 \%$, obtained after applying a 7.5M-2.5GGBS ratio of 3:1 over 7 days of curing. However, all other specimens exhibited low swelling. For example, the swelling of soil samples stabilized with 5M-15GGBS and 2.5M-17.5GGBS was $0.001 \%$ and $0.005 \%$ after 90 days of curing, with swelling magnitude almost wholly suppressed to $99.95 \%$ and $99.77 \%$. The reduction in the swelling values was because of the use of GGBS, which exhibited superior sulphate resistance along with its denser structure and lower $\mathrm{Ca}^{2+}$ content $[8,45]$.

\subsubsection{Effects of M-GGBS-MK on Swelling}

Figures 16-18 reveal that the use of the M-GGBS-MK stabilizer (10 and $20 \mathrm{wt}$. \%) modified the behavior of the volumetric change and significantly reduced the extent of swelling of the gypseous soil. After 28 days of observation, the swelling magnitudes for 5M-2.5GGBS-2.5MK, 5M-5GGBS-10MK, 5M-10GGBS-5MK, and 5M-12.5GGBS-2.5MK were $0.105 \%, 0.254 \%, 0.208 \%$, and $0.04 \%$, respectively, with swelling values suppressed to $98.79 \%$, $97.09 \%, 97.62 \%$, and $99.54 \%$ respectively. Nevertheless, the long curing period (90 days) produced further declines in the swelling rate, thereby achieving minimum swellings of $0.005 \%, 0.067 \%, 0.043 \%$, and $0.001 \%$, where the swelling was roughly inhibited to $99.77 \%$, $96.92 \%, 98.06 \%$, and $99.95 \%$ respectively.

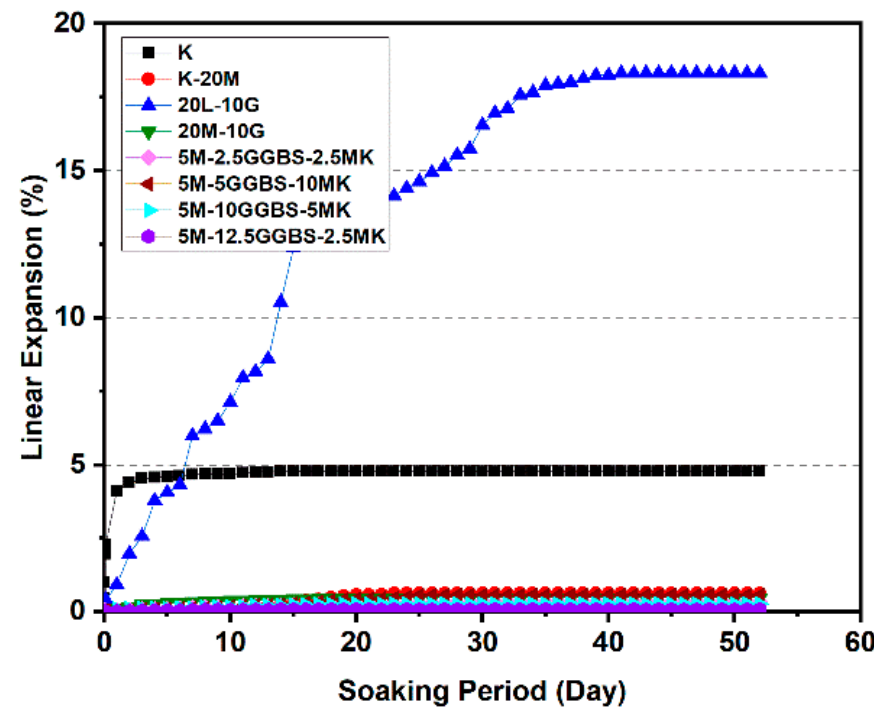

(a)

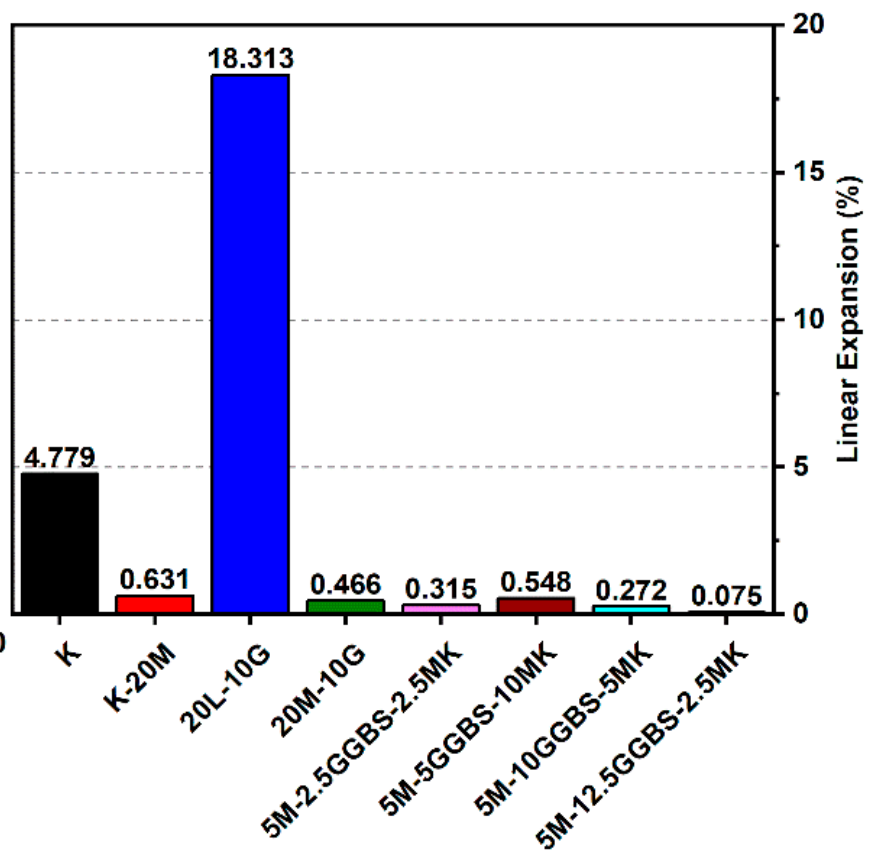

(b)

Figure 16. Vertical swelling strain of soils stabilized with $10 \%$ and $20 \%$ of L, M, and M-GGBS-MK after 7 days of curing: (a) results presented as a line curve, (b) results presented as columns. 


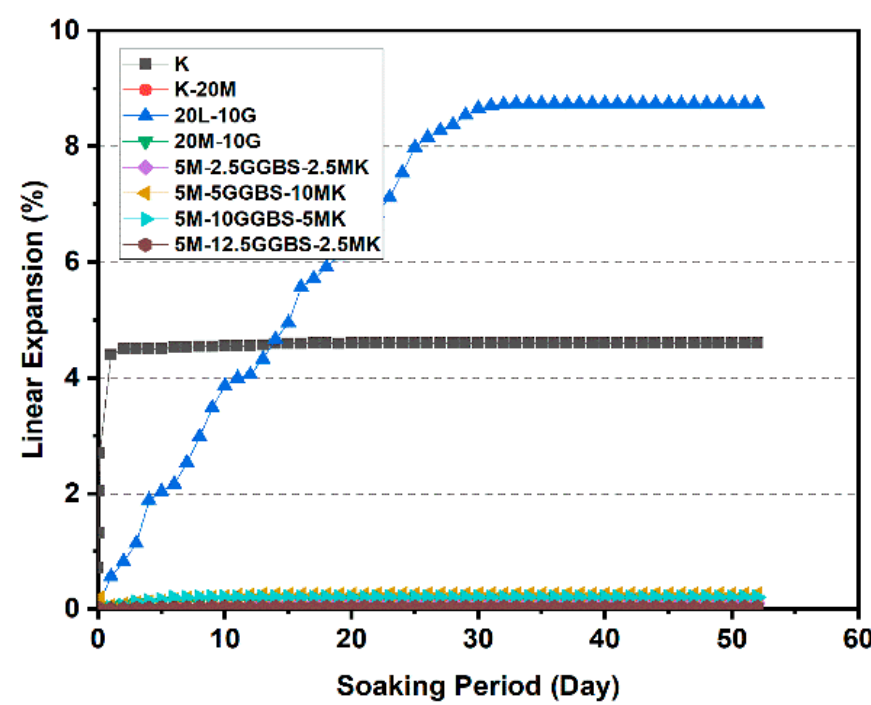

(a)

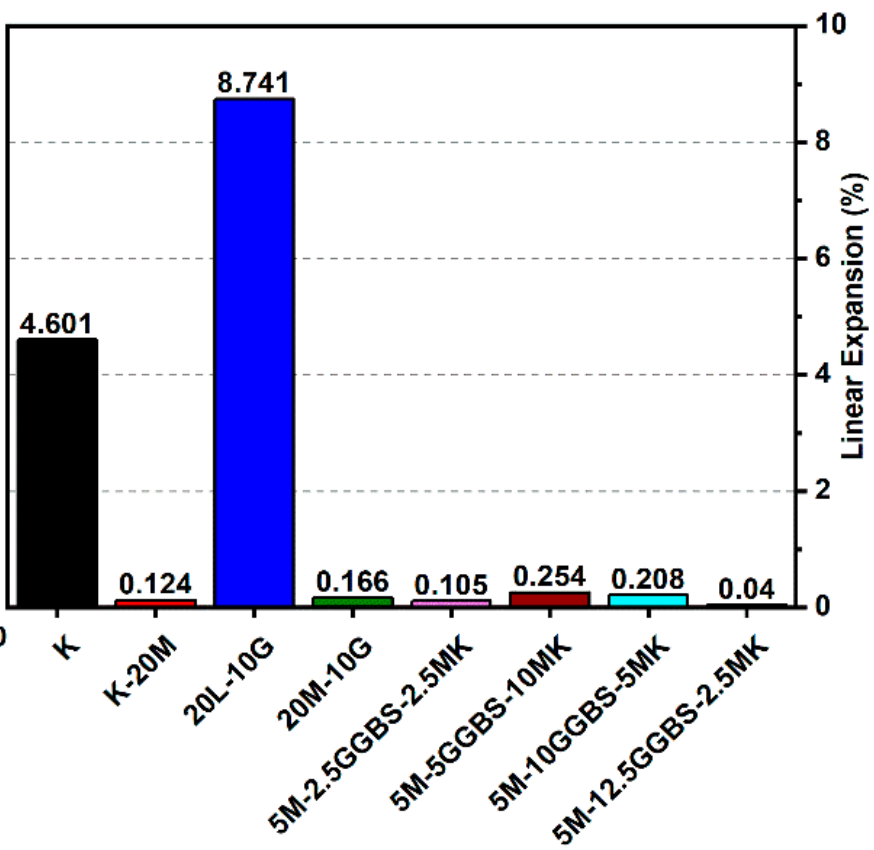

(b)

Figure 17. Vertical swelling strain of soils stabilized with $10 \%$ and $20 \%$ of L, M, and M-GGBS-MK after 28 days of curing: (a) results presented as a line curve, (b) results presented as columns.

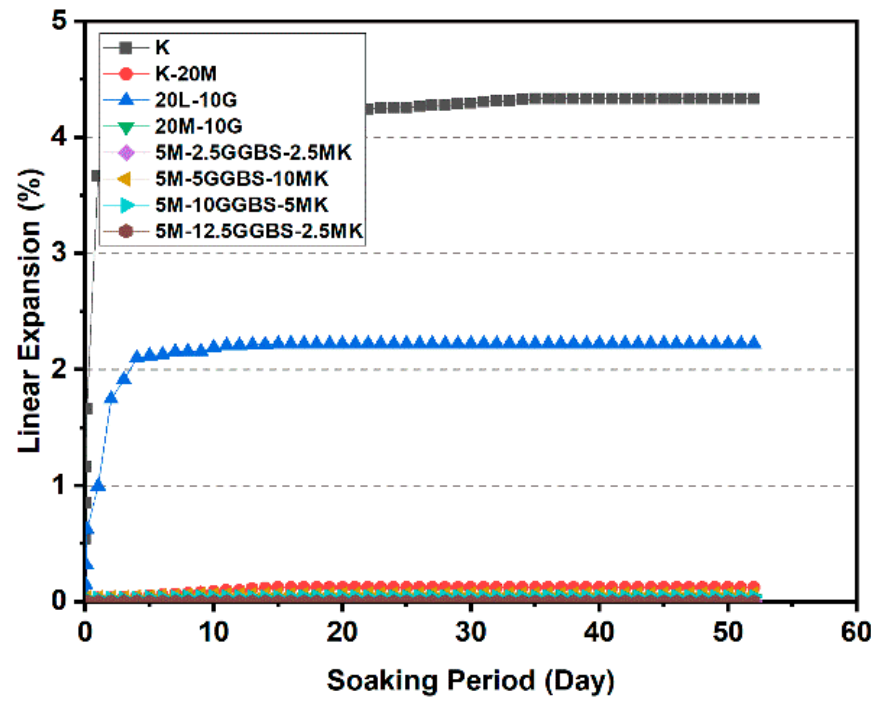

(a)

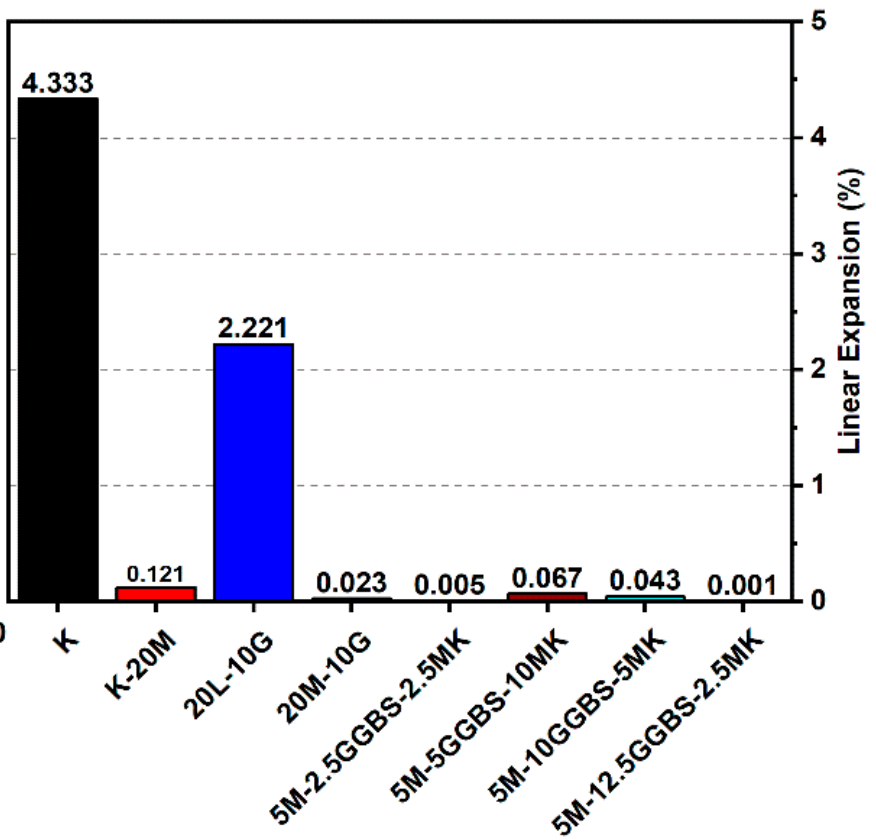

(b)

Figure 18. Vertical swelling strain of soils stabilized with $10 \%$ and $20 \%$ of L, M, and M-GGBS-MK after 90 days of curing: (a) results presented as a line curve, (b) results presented as columns.

Results from the linear expansion test indicated that swelling behavior disappeared in the high-sulphate soil, which was treated with the M-GGBS-MK-stabilizer. The volume changes of the treated soils were less than those of the lime-treated soils, indicating that the swelling characteristics were enhanced in the treated high-sulphate soils. 
These results indicate that the M-GGBS-MK-stabilized soil resisted sulphate attacks better than the soil stabilized with lime. Moreover, the results showed that the swelling of the soil stabilized with lime was better than that of soil stabilized with M-GGBS-MK at prolonged curing periods. The phenomenon can be explained by two factors: (1) A larger amount of calcium in the lime-stabilized soil contributed to ettringite formation in the presence of sulphate and (2) the consumption of calcium by sulphate, which led to a reduction in the formation of cementitious material such as $\mathrm{CSH}, \mathrm{CAH}$, and CSAH. Adeleke et al. [5] reported that there are various levels of swelling. In this study, the mixing of K-10L-10G and K-20L-10G soils, give the maximum expansion of $25.226 \%$ and $18.313 \%$. Based on the level of swelling as shown in Table 7, the soil samples (K-10L-10G and K-20L-10G) can cause excessive swelling when they come into contact with water because the maximum expansion is more than $2 \%$.

Table 7. Levels of swelling for clay soil.

\begin{tabular}{cc}
\hline Swelling (\%) & Swelling Level \\
\hline 0 & No swell \\
$0-0.1$ & Negligible \\
$0.1-0.5$ & Light \\
$0.5-1.0$ & Medium \\
$1.0-2.0$ & Strong \\
Over 2.0 & Very strong \\
\hline
\end{tabular}

\subsection{Flexural Strength Flexural (FS)}

Flexural load curves for the kaolin clay and sulphate-bearing soil along with the calcium-based stabilizer (L) and non-calcium-based stabilizer (M) with the inclusion of MK, GGBS, and GGBS-MK ratios of $10 \%$ and 20\% after curing for 7, 28 and 90 days, are shown in Figures 19 and 20. The kaolin clay curve exhibited a flexural strength of $132.44 \mathrm{kPa}$ after curing for 90 days. In contrast, the curves produced by the $\mathrm{M}$ stabilizer mixtures showed a slight improvement with and without the presence of sulphate, which is a direct measure of the flexural strength of the specimens. When compared to specimens treated with the L stabilizer, the flexural strength was less with the presence of sulphate. Furthermore, using $10 \%$ and $20 \%$ of the M-MK, M-GGBS, and M-GGBS-MK stabilizers significantly improved the peak flexural load; this was more significant for the $20 \%$ M-GGBS content. The flexural strength of the M-GGBS mixture with $10 \%$ and $20 \%$ content reached 2253.09 and $4627.53 \mathrm{kPa}$ after curing for 90 days, respectively, gaining values $472.4 \%$ and $522.62 \%$ higher than those of the L stabilizer (393.6 and $743.23 \mathrm{kPa}$ ) using $10 \%$ and $20 \%$ mixtures, respectively, after 90 days of curing.

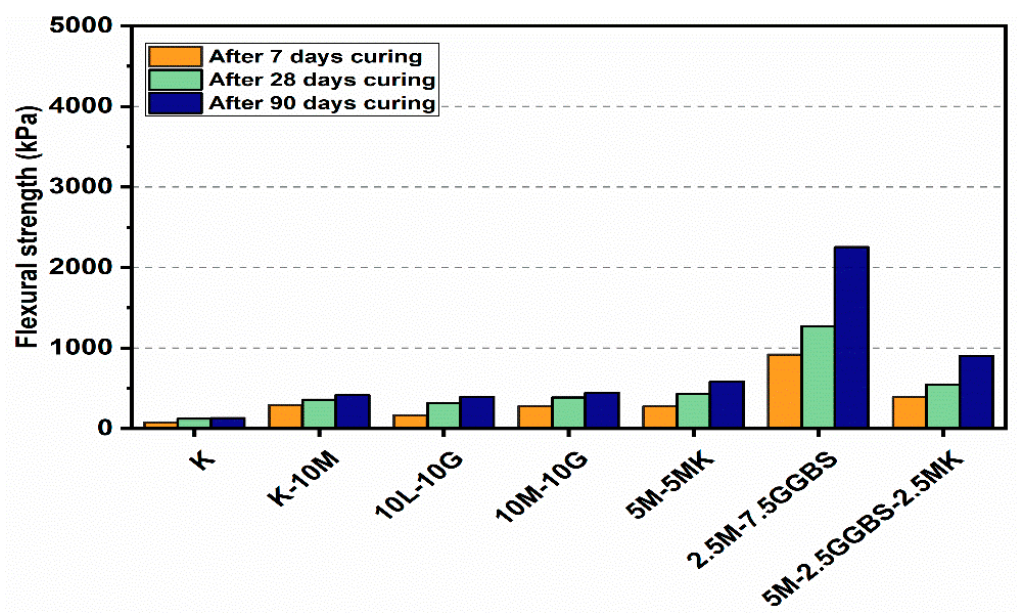

Figure 19. Flexural load curves of test gypseous soils treated with $10 \%$ mixture content after 7,28 and 90 days of curing. 


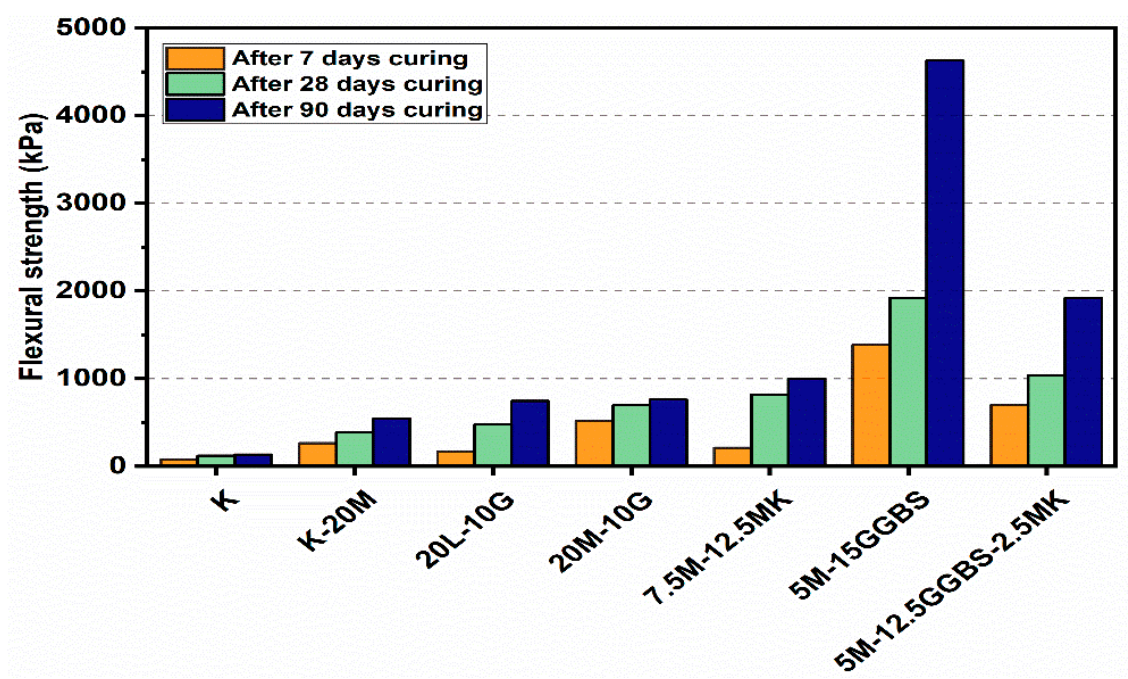

Figure 20. Flexural load curves of test gypseous soils treated with $20 \%$ mixture content after 7,28 and 90 days of curing.

\subsection{SEM and EDX Analysis}

The SEM images of the gypseous soil-lime mixture after 90 days of curing showed that a significant amount of crystalline mineral needles (ettringite) had formed, as shown in Figures 21a and 22a. This resulted in a decrease in strength, a high capacity for swelling, and the destruction of the soil specimen's structure. The improvement in the gypseous soil samples was determined by measuring the $\mathrm{Si} / \mathrm{Al}$ ratio (\%) utilizing EDX to explain the strength development. Higher $\mathrm{Si} / \mathrm{Al}$ ratios generally led to the formation of more $\mathrm{Si}-\mathrm{O}-\mathrm{Si}$ bonds which further increased the mechanical strength of the soil sample [55]. The $\mathrm{Si} / \mathrm{Al}$ ratio in the (10\% and $20 \%$ ) L-G specimens obtained from the EDX pattern ranged from 1.06 to 1.12, which was low due to the ettringite formation and high porosity in the microstructure of the samples. The EDX pattern of the gypseous soil-lime mixture and its elemental composition is represented in Figures $21 b$ and 22b.

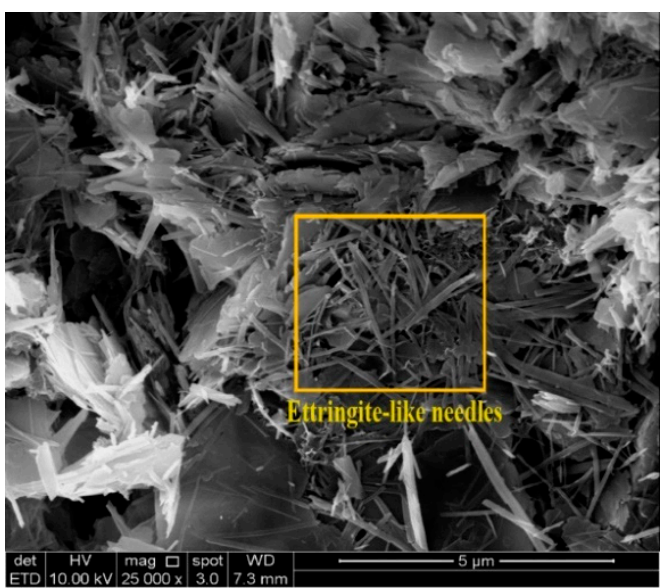

(a)

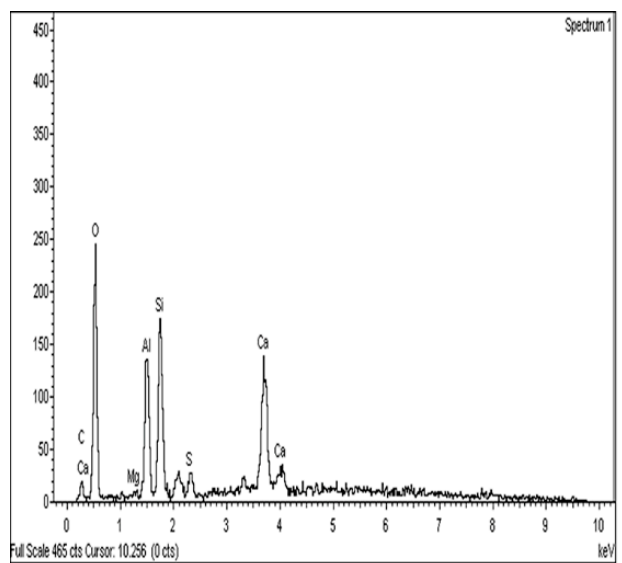

(b)

Figure 21. SEM photo and EDX spectrograph of stabilized gypseous soils after 90 days of curing: (a) SEM photo of 10L:10G and (b) EDX spectrograph of 10L:10G. 


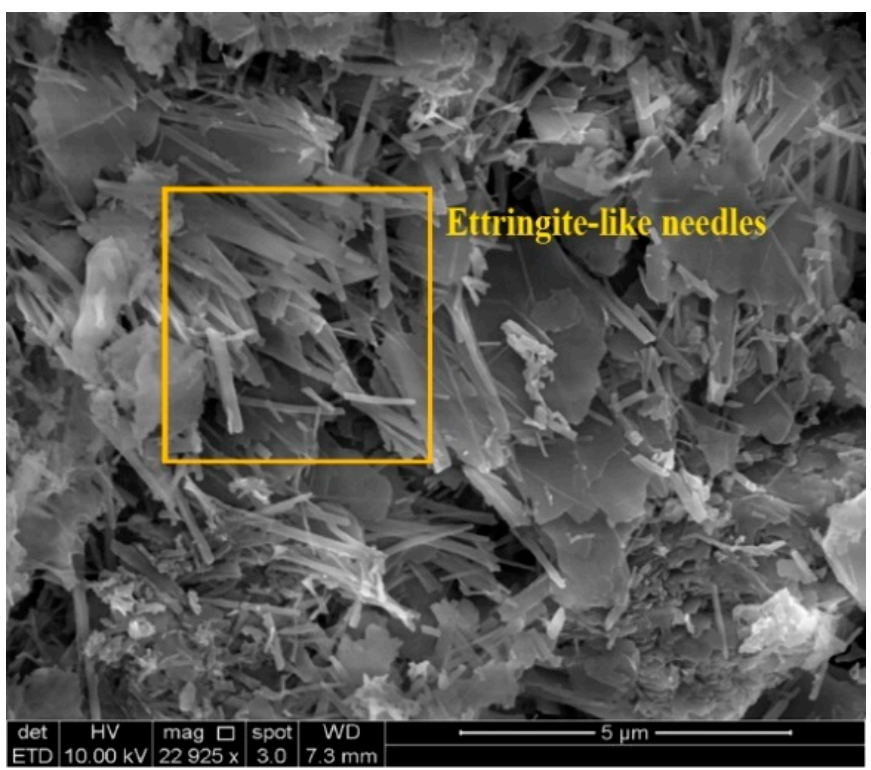

(a)

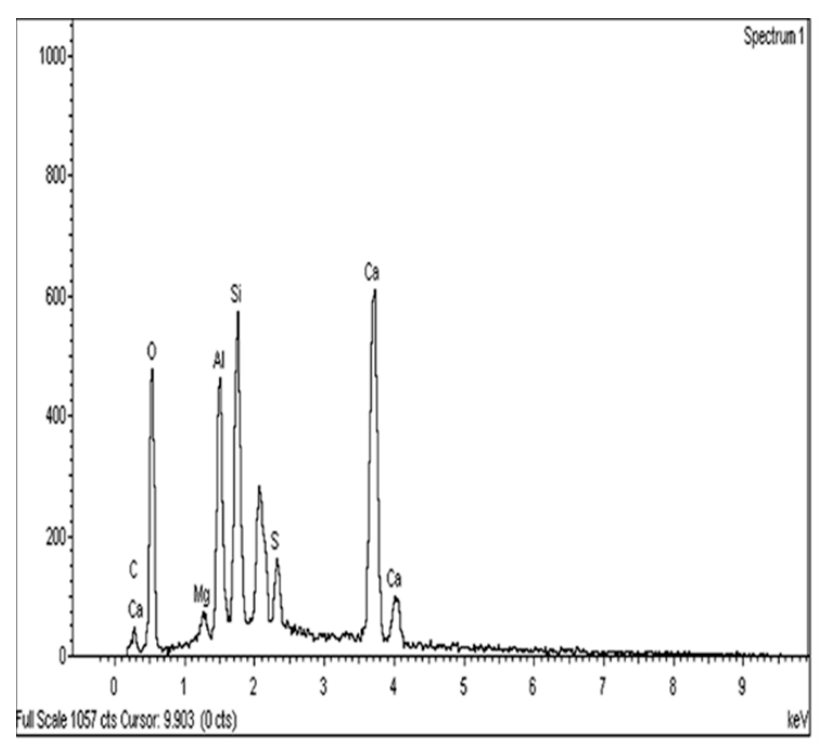

(b)

Figure 22. SEM photo and EDX spectrograph of stabilized gypseous soils after 90 days of curing: (a) SEM photo of 20L:10G and (b) EDX spectrograph of 20L:10G.

Figures 23a and 24a show SEM observation images of the sulphate soil-M-G mixture, revealing spherical and irregular particles of magnesium silicate hydrate $(\mathrm{MCH})$. The EDX information showed a slight increase in the Si/Al ratio (1.1 and 1.14) for M-Gstabilizer specimens with $10 \%$ and $20 \%$ compared to the L-G specimens (1.06 and 1.12), which was probably due to the absence of ettringite and the formation of MSH product. Figures $23 \mathrm{~b}$ and $24 \mathrm{~b}$, respectively, present the EDS spectrum and elemental composition of the gypseous soil-M-G mixture.

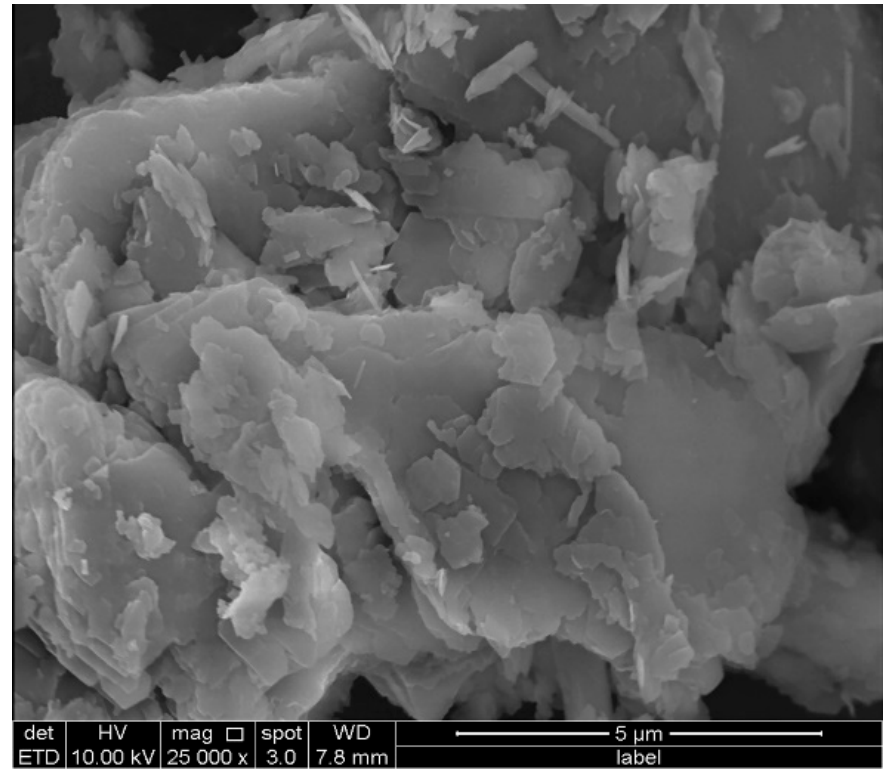

(a)

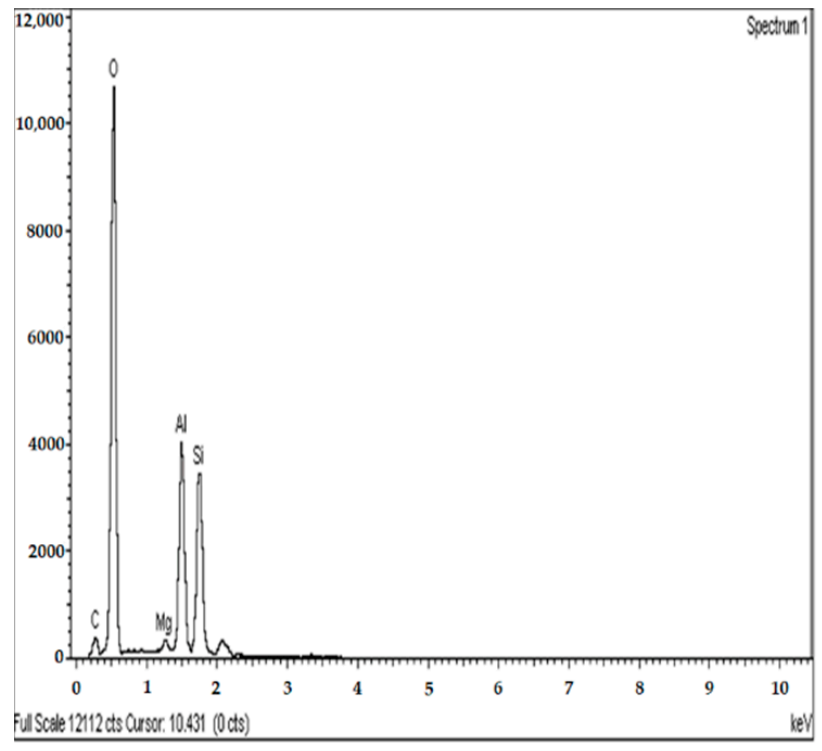

(b)

Figure 23. SEM photo and EDX spectrograph of stabilized gypseous soils after 90 days of curing: (a) SEM photo of 10M:10G and (b) EDX spectrograph of 10M:10G. 


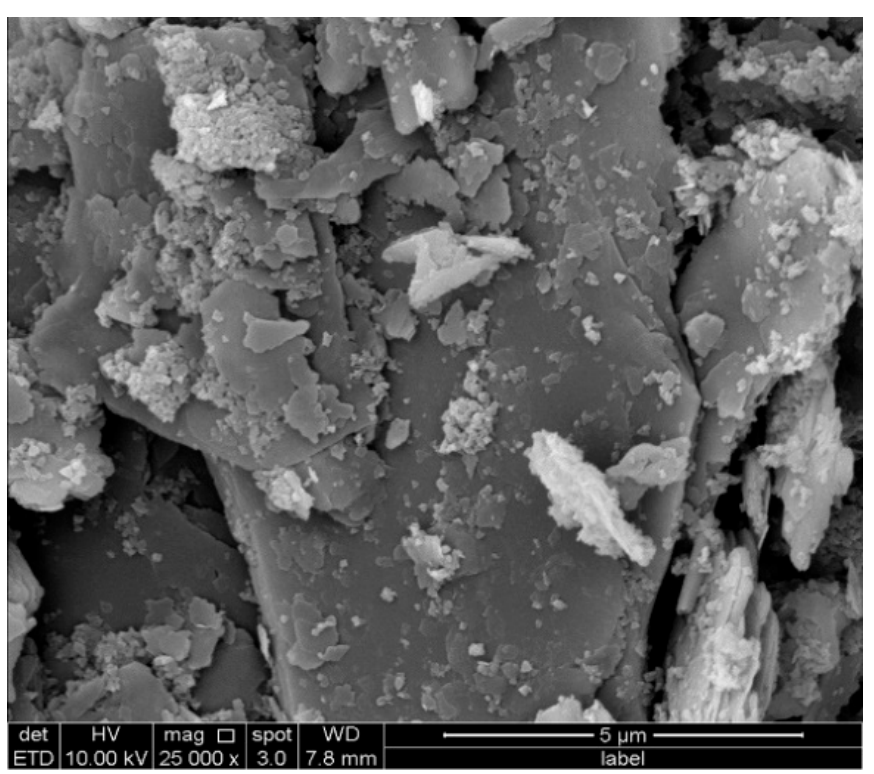

(a)

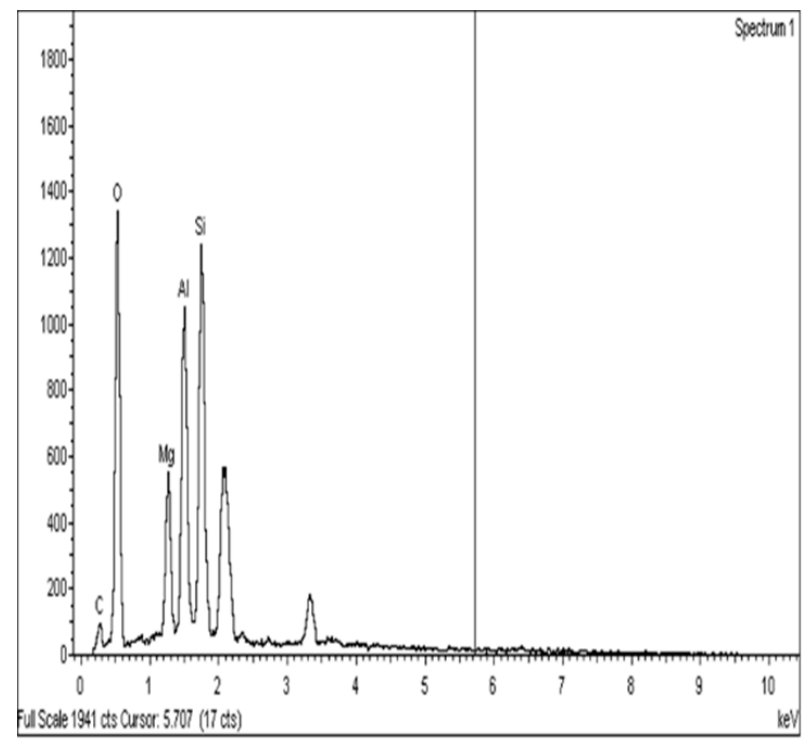

(b)

Figure 24. SEM photo and EDX spectrograph of stabilized gypseous soils after 90 days of curing: (a) SEM photo of 20M:10G and (b) EDX spectrograph of 20M:10G.

Figures 25a, 26a and 27a show the SEM observation images of M-GGBS, M-MK, and M-GGBS-MK, respectively. Regarding the surface features and particle shape, M-GGBS differed significantly from M-MK and M-GGBS-MK. M-MK and M-GGBS-MK particles were spherical, as shown in Figures 25a and 27a. The surface of the particles was shiny and devoid of dust. For the M-GGBS particles, they were irregular and angular, and the presence of plate-shaped particles was evident (Figure 26a), which had rough, gritty surface textures. Figures 25a, 26a and 27a show the surface morphologies of the soil-M-GGBS, -M-MK, and -M-GGBS-MK specimens after 90 days of curing. As indicated, no ettringite formation was observed. This proves that the addition of M with GGBS and MK as a stabilizing agent contributed to the formation of CSH gel significantly. Some crystalline structures, such as MSH (magnesium silicate hydrate), were also observed. The pozzolanic activity occurring between M, GGBS, and MK as a stabilizer and clay was attributed to the formation of $\mathrm{CSH}$ gel. Based on the results derived from the EDX spectrum, the highest $\mathrm{Si} / \mathrm{Al}$ ratios $(1.22,1.59$, and 1.28) were observed in the 7.5M-12.5MK, 5M-15GGBS, and 5M-12.5GGBS2.5MK samples, respectively. This improvement was due to GGBS and MK dissolving in an alkaline activator to generate extra soluble alumina and silica, which increased the $\mathrm{Si} / \mathrm{Al}$ ratio of the specimen, leading to the complete activation of the particles producing calcium-alumino-silicate hydrate (CASH) in the matrix. Figures 25b, 26b and 27b show the EDS spectrum and elemental composition of the gypseous soil-M-GGBS, -M-MK, and -M-GGBS-MK mixtures, respectively.

The increase in UCS value with prolonged curing periods could have been due to cementing gel formation from the interaction of the soil with the nanoparticles, which improved the UCS of the treated samples as a result of the improved soil particle bonding [56,57]. 


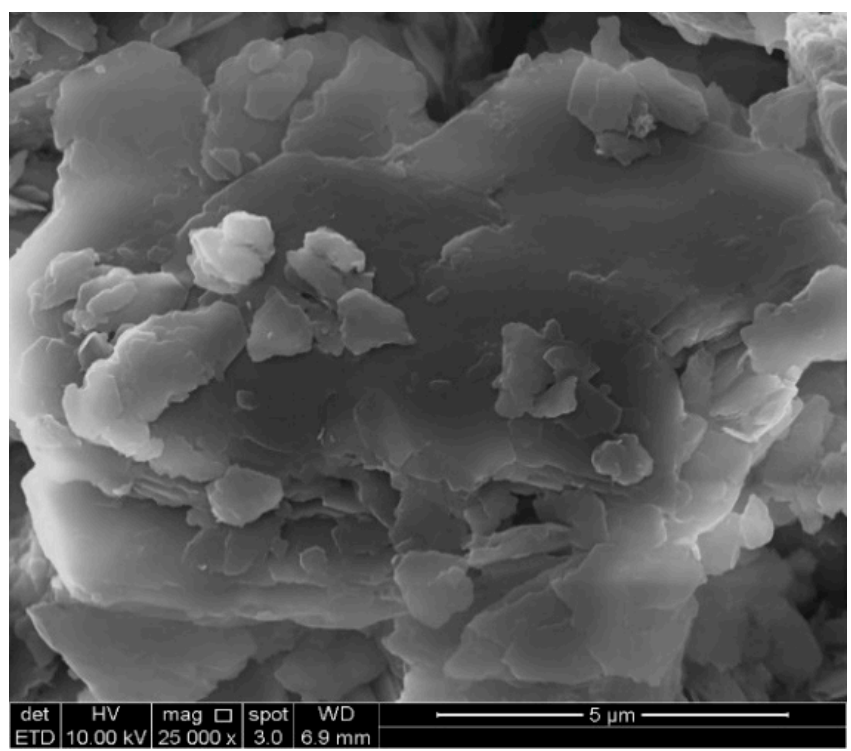

(a)

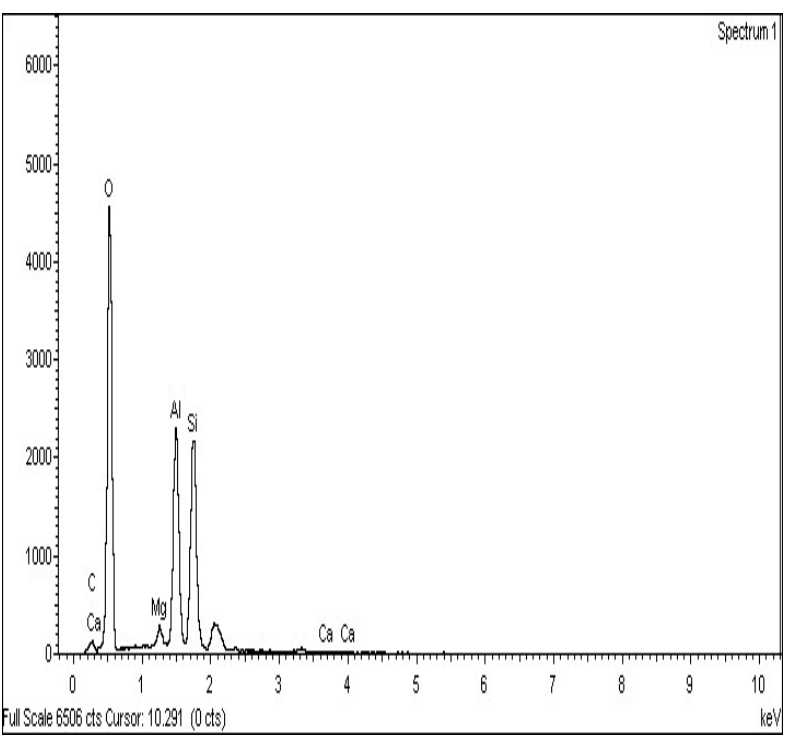

(b)

Figure 25. SEM photo and EDX spectrograph of stabilized gypseous soils after 90 days of curing: (a) SEM photo of 7.5M:12.5MK and (b) EDX spectrograph of 7.5M:12.5MK.

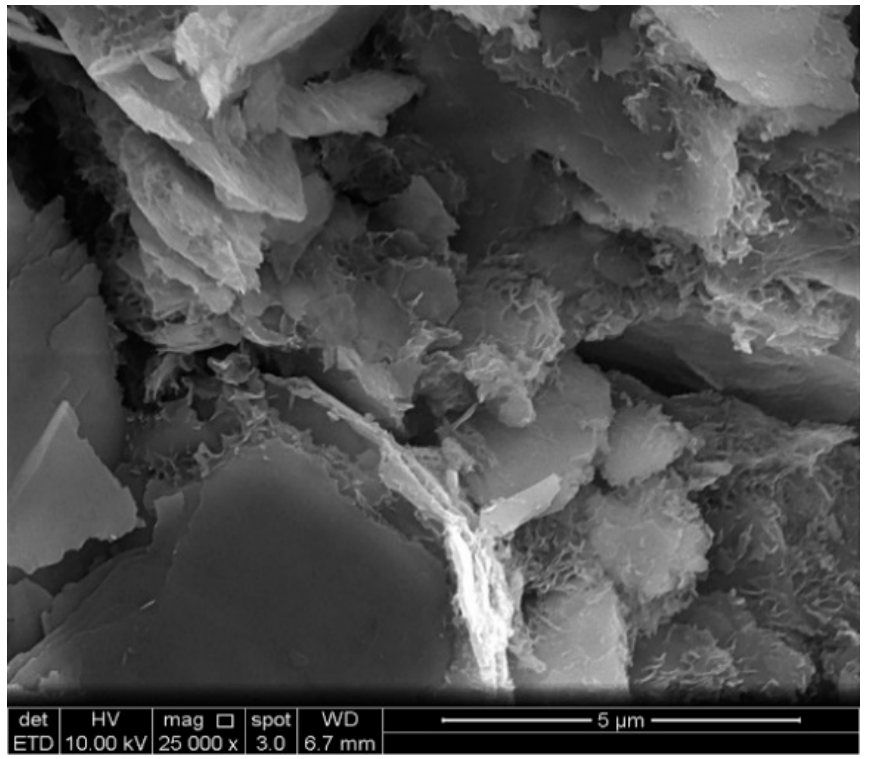

(a)

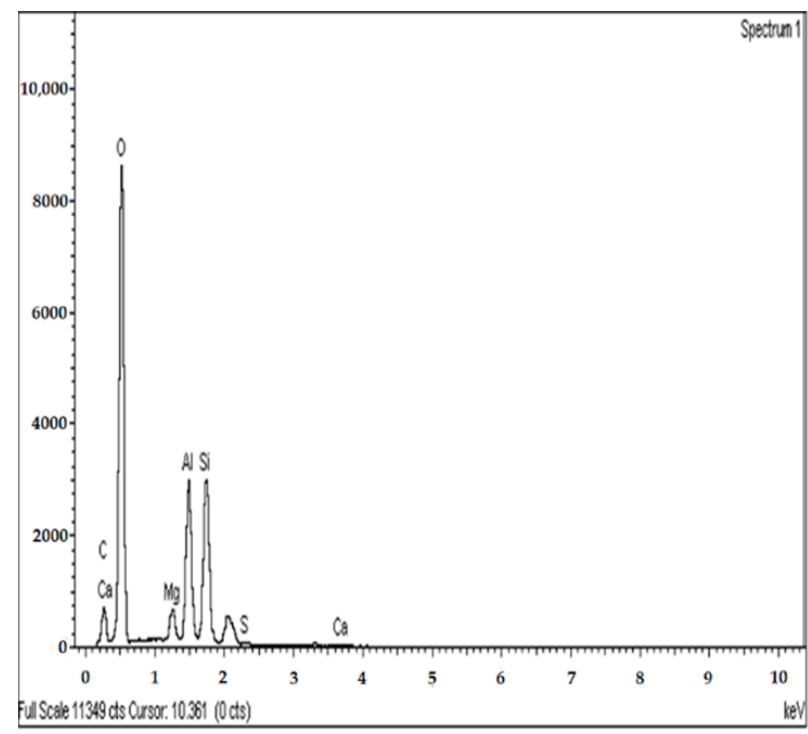

(b)

Figure 26. SEM photo and EDX spectrograph of stabilized gypseous soils after 90 days of curing: (a) SEM photo of 5M:15GGBS and (b) EDX spectrograph of 5M:15GGBS. 


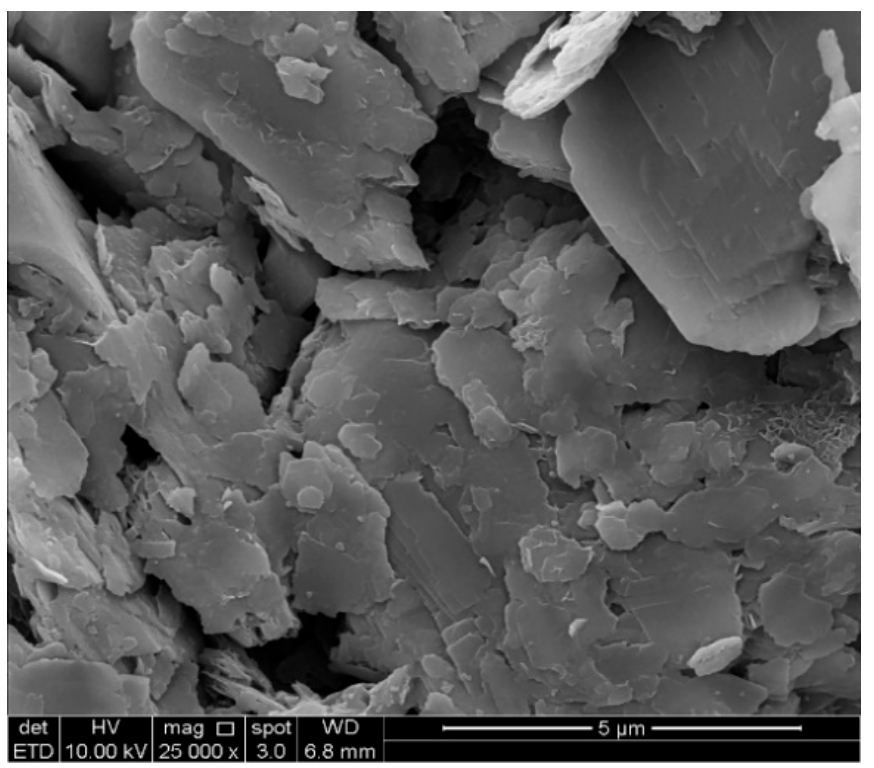

(a)

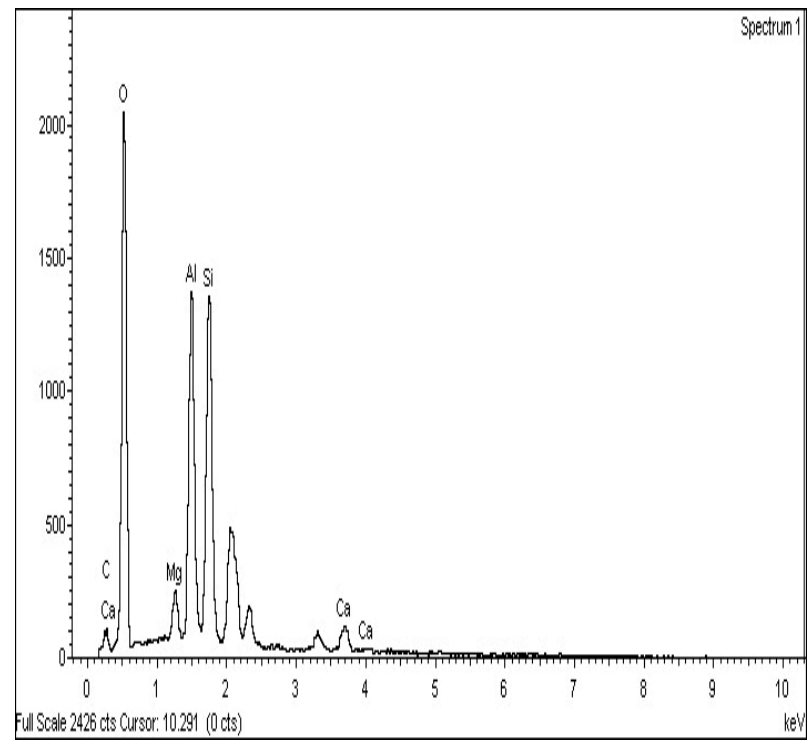

(b)

Figure 27. SEM photo and EDX spectrograph of stabilized gypseous soils after 90 days of curing: (a) SEM photo of 5M:12.5GGBS:2.5MK and (b) EDX spectrograph of 5M-12.5GGBS:2.5MK.

\section{Conclusions}

Sulphate-bearing soils cause major issues in pavement and various civil engineering infrastructures due to their causing significant swelling and strength damage. The results of this study portrayed the impacts of $(\mathrm{M})$ as a non-calcium-based stabilizer, metakaolin, and GGBS as abundant by-products in treating gypseous soil with a high level of sulphate. Based on the results of the study, the following conclusions were made:

- The minimum swelling values of M-MK-, M-GGBS-, and M-GGBS-MK-stabilized gypseous soils with $20 \%$ doses $(0.004 \%, 0.001 \%$, and $0.001 \%)$ were lower than that of lime-stabilized soil.

- The optimum strength values of M-MK-, M-GGBS, and M-GGBS-MK-stabilized soils after soaking with $20 \%(0.96,12.8$, and $3.72 \mathrm{MPa})$ were notably higher than that of lime-stabilized soil (0.9 MPa).

- The period of curing significantly affected the sample's resistance to sulphate attack due to the impact of the hydration process. Extension of the curing time from 7 to 90 days caused adequate hydration and greater strength in the presence of sulphate (gypsum).

- $\quad$ SEM and EDX analysis showed no evidence of ettringite formation in the soil samples stabilized with M-MK-, M-GGBS-, and M-GGBS-MK.

- The formation of cementing gels such as MSH, MAH, CSH, and CAH improved the UCS values of the stabilized samples, as these gels occupied the voids and improved the bonding between the soil particles. As a result, the treated soils' UCS values were improved.

- The M-MK, M-GGBS, and M-GGBS-MK were demonstrated as suitability and effective agents for the stabilization of gypseous soil.

Author Contributions: K.I.A.E. and A.M.A.E. designed and performed the experimental program; K.I.A.E. and M.A.M.I. collected and analyzed the experimental data; A.M.A.E. wrote, reviewed, and edited the manuscript; and M.A.M.I. provided supervision of the manuscript writing. All authors have read and agreed to the published version of the manuscript.

Funding: This work was funded by Universiti Sains Malaysia. 
Institutional Review Board Statement: Not applicable.

Informed Consent Statement: Not applicable.

Data Availability Statement: Not applicable.

Acknowledgments: The authors would like to acknowledge the Universiti Sains Malaysia for its financial support.

Conflicts of Interest: The authors declare no conflict of interest.

$\begin{array}{ll}\text { Abbreviations } \\ \text { K } & \text { Kaolin } \\ \text { G } & \text { Gypsum } \\ \text { L } & \text { Hydrated Lime } \\ \text { MgO } & \text { Magnesium Oxide } \\ \text { M } & \text { Nano-Magnesium Oxide } \\ \text { MK } & \text { Metakaolin } \\ \text { GGBS } & \text { Ground Granulated Blast-Furnace Slag } \\ \text { PC } & \text { Portland Cement } \\ \text { CSH } & \text { Calcium Silicate Hydrates } \\ \text { CAH } & \text { Calcium Aluminate Hydrates } \\ \text { CASH } & \text { Calcium Aluminosilicate Hydrates } \\ \text { LP } & \text { Linear Expansion Tests } \\ \text { UCS } & \text { Unconfined Compressive Strength } \\ \text { FS } & \text { Flexural Strength } \\ \text { P } & \text { Maximum Load Applied } \\ \text { L } & \text { Support Span } \\ \text { r } & \text { Sample Radius } \\ \text { SEM } & \text { energy dispersive spectroscopy } \\ \text { EDS } & \text { scanning electron microscopy }\end{array}$

\section{References}

1. Hozatloglu, D.T.; Y1lmaz, I. Shallow mixing and column performances of lime, fly ash and gypsum on the stabilization of swelling soils. Eng. Geol. 2021, 280, 105931. [CrossRef]

2. Cai, G.; Liu, S.; Du, G.; Chen, Z.; Zheng, X.; Li, J. Mechanical performances and microstructural characteristics of reactive MgO-carbonated silt subjected to freezing-thawing cycles. J. Rock Mech. Geotech. Eng. 2021, 13, 875-884. [CrossRef]

3. Sindhu, A.R.; Minukrishna, P.; Abraham, B.M. Experimental Study on the Impact of Type of Sulphate in Lime Stabilised Clays. In Proceedings of the International Web Conference in Civil Engineering for a Sustainable Planet, Online, 5-6 March 2021.

4. Caselles, L.D. Stabilisation des Sulfates et du Molybdène par des Liants Alternatifs; University of Toulouse: Toulouse, France, 2020.

5. Adeleke, B.; Kinuthia, J.; Oti, J. Strength and Swell Performance of High-Sulphate Kaolinite Clay Soil. Sustainability 2020, $12,10164$. [CrossRef]

6. Li, W.; Yi, Y.; Puppala, A.J. Suppressing Ettringite-Induced Swelling of Gypseous Soil by Using Magnesia-Activated Ground Granulated Blast-Furnace Slag. J. Geotech. Geoenviron. Eng. 2020, 146, 1-6. [CrossRef]

7. Aldaood, A.; Bouasker, M. Mechanical Behavior of Gypseous Soil Treated with Lime. Geotech. Geol. Eng. 2020, 39, 719-733. [CrossRef]

8. Seco, A.; del Castillo, J.M.; Espuelas, S.; Marcelino, S.; García, B. Sulphate soil stabilisation with magnesium binders for road subgrade construction. Int. J. Pavement Eng. 2020, 1-11. [CrossRef]

9. Raja, P.S.; Thyagaraj, T. Significance of compaction time delay on compaction and strength characteristics of sulfate resistant cement-treated expansive soil. J. Rock Mech. Geotech. Eng. 2021. [CrossRef]

10. Eyo, E.U.; Abbey, S.J.; Ngambi, S.; Ganjian, E.; Coakley, E. Incorporation of a nanotechnology-based product in cementitious binders for sustainable mitigation of sulphate-induced heaving of stabilised soils. Eng. Sci. Technol. Int. J. 2020, $24,436-448$. [CrossRef]

11. Khadka, S.D.; Jayawickrama, P.W.; Senadheera, S.; Segvic, B. Stabilization of highly expansive soils containing sulfate using metakaolin and fly ash based geopolymer modified with lime and gypsum. Transp. Geotech. 2020, 23, 100327. [CrossRef]

12. Bazyar, M.H.; Ebrahimi, M.; Lenjani, M.Z.; Makarchian, M. The Effect of Rice Husk Ash on Mechanical Properties of Clayey Soils Stabilized with Lime in the Presence of Sulphate. J. Eng. Geol. 2017, 11, $23-52$.

13. Abdi, M.R.; Askarian, A.; Safdari Seh Gonbad, M. Effects of sodium and calcium sulphates on volume stability and strength of lime-stabilized kaolinite. Bull. Eng. Geol. Environ. 2019, 79, 941-957. [CrossRef] 
14. Wang, L.; Liu, J.; Yu, X.; Li, X.; Puppala, A.J.; Wang, Q. Experimental study on the correlation between the partial and total salt content in saline gravel using ion chromatography. Transp. Geotech. J. 2021, 26, 100424. [CrossRef]

15. Caselles, L.D.; Hot, J.; Roosz, C.; Cyr, M. Stabilization of soils containing sulfates by using alternative hydraulic binders. Appl. Geochem. 2020, 113, 113. [CrossRef]

16. Chakkor, O.; Altan, M.F.; Canpolat, O. Metakaolin and Red-Mud Based Geopolymer: Resistance to Sodium and Magnesium Sulfate Attack. Celal Bayar Univ. J. Sci. 2021, 17, 101-113. [CrossRef]

17. Akula, P.; Little, D.N. Coupled thermodynamic and experimental approach to evaluate ettringite formation in a soil stabilized with fluidized bed ash by-product: A case study. Transp. Geotech. 2020, 23, 100352. [CrossRef]

18. Wang, P.; Ye, Y.; Zhang, Q.; Liu, J.; Yao, J. Investigation on the sulfate attack-induced heave of a ballastless track railway subgrade. Transp. Geotech. 2020, 23, 100316. [CrossRef]

19. Chen, W.; Huang, B.; Yuan, Y.; Deng, M. Deterioration process of concrete exposed to internal sulfate attack. Materials 2020, 13, 1336. [CrossRef]

20. Sun, Z.; Zhou, J.; Qi, Q.; Li, H.; Zhang, N.; Mu, R. Influence of fly ash on mechanical properties and hydration of calcium sulfoaluminate-activated supersulfated cement. Materials 2020, 13, 2514. [CrossRef]

21. Kampala, A.; Jitsangiam, P.; Pimraksa, K.; Chindaprasirt, P. An investigation of sulfate effects on compaction characteristics and strength development of cement-treated sulfate bearing clay subgrade. Road Mater. Pavement Des. 2020, 1-14. [CrossRef]

22. Talluri, N.; Puppala, A.J.; Congress, S.S.C.; Banerjee, A. Experimental Studies and Modeling of High Sulfate Soil Stabilization. J. Geotech. Geoenviron. Eng. 2020, 146, 1-16. [CrossRef]

23. Zhang, G.; Wu, C.; Hou, D.; Yang, J.; Sun, D.; Zhang, X. Effect of environmental pH values on phase composition and microstructure of Portland cement paste under sulfate attack. Compos. Part B 2021, 216, 108862. [CrossRef]

24. Jin, F.; Al-Tabbaa, A. Evaluation of novel reactive $\mathrm{MgO}$ activated slag binder for the immobilisation of lead and zinc. Chemosphere 2014, 117, 285-294. [CrossRef] [PubMed]

25. Cai, G.H.; Liu, S.Y.; Zheng, X. Influence of drying-wetting cycles on engineering properties of carbonated silt admixed with reactive MgO. Constr. Build. Mater. 2019, 204, 84-93. [CrossRef]

26. Yi, Y.; Liska, M.; Al-Tabbaa, A. Initial investigation into the use of GGBS-MgO in soil stabilisation. Grouting Deep Mix. 2012, 2012, 444-453.

27. Yi, Y.; Liska, M.; Jin, F.; Al-tabbaa, A. Mechanism of reactive magnesia—Ground granulated blastfurnace slag (GGBS) soil stabilization. Can. Geotech. J. 2016, 55, 773-782. [CrossRef]

28. Ehwailat, K.I.A.; Ismail, M.A.M.; Ezreig, A.M.A. Novel Approach for Suppression of Ettringite Formation in Sulfate-Bearing Soil Using Blends of Nano-Magnesium Oxide, Ground Granulated Blast-Furnace Slag and Rice Husk Ash. Appl. Sci. 2021, 11, 6618. [CrossRef]

29. ASTM C618-05 (AASHTOM295). Standard Specification for Coal Fly Ash and Raw or Calcined Natural Pozzolan for Use in Concrete; ASTM International: West Conshohocken, PE, USA, 2005.

30. AASHTO. Standard Specifications for Transportation Materials and Methods of Sampling and Testing, 14th ed.; American Association for State Highway and Transportation Officials: Washington, DC, USA, 1996.

31. Bayang, F.; Academy, N.D.; Garba, H.; Academy, N.D.; Sani, J.E.; Academy, N.D. Laboratory Assessment of Metakaolin Effect on the Volumetric Shrinkage of Black Cotton Soil for Flexible Pavement Construction. Civ. Environ. Res. 2017, 9, 16-29.

32. Billong, N.; Kinuthia, J.; Oti, J.; Melo, U.C. Performance of sodium silicate free geopolymers from metakaolin (MK) and Rice Husk Ash (RHA): Effect on tensile strength and microstructure. Constr. Build. Mater. 2018, 189, 307-313. [CrossRef]

33. Thankam, G.L.; Thurvas Renganathan, N. Ideal supplementary cementing material Metakaolin: A review. Int. Rev. Appl. Sci. Eng. 2020, 11, 58-65. [CrossRef]

34. Seco, A.; Miqueleiz, L.; Prieto, E.; Marcelino, S.; García, B.; Urmeneta, P. Sulfate soils stabilization with magnesium-based binders. Appl. Clay Sci. 2017, 135, 457-464. [CrossRef]

35. Pai, R.R.; Patel, S.; Bakare, M.D. Applicability of Utilizing Stabilized Native Soil as a Subbase Course in Flexible Pavement. Indian Geotech. J. 2020, 50, 289-299. [CrossRef]

36. Truong, S.B.; Thi, N.N.; Thanh, D.N. An Experimental Study on Unconfined Compressive Strength of Soft Soil-Cement Mixtures with or without GGBFS in the Coastal Area of Vietnam. Adv. Civ. Eng. 2020, 2020, 20-25. [CrossRef]

37. Yi, Y.; Liska, M.; Al-Tabbaa, A. Properties of Two Model Soils Stabilized with Different Blends and Contents of GGBS, MgO, Lime, and PC. J. Mater. Civ. Eng. 2014, 26, 267-274. [CrossRef]

38. YI, Y.; LI, C.; LIU, S.; AL-TABBAA, A. Resistance of MgO-GGBS and CS-GGBS stabilised marine soft clays to sodium sulfate attack. Géotechnique 2014, 64, 673-679. [CrossRef]

39. Sarkkinen, M.; Kujala, K.; Gehör, S. Efficiency of MgO activated GGBFS and OPC in the stabilization of highly sulfidic mine tailings. J. Sustain. Min. 2019, 18, 115-126. [CrossRef]

40. Yu, B.W.; Du, Y.J.; Jin, F.; Liu, C.Y. Multiscale study of sodium sulfate soaking durability of low plastic clay stabilized by reactive magnesia-activated ground granulated blast-furnace slag. J. Mater. Civ. Eng. 2016, 28, 1-10. [CrossRef]

41. Shah, V.; Scott, A. Hydration and microstructural characteristics of $\mathrm{MgO}$ in the presence of metakaolin and silica fume. Cem. Concr. Compos. 2021, 121, 104068. [CrossRef]

42. British Standards Institution. BS EN ISO 17892-4:2016: Geotechnical Investigation and Testing. Laboratory Testing of Soil Part 4: Determination of Particle Size Distribution; BSI Standards Ltd.: London, UK, 2014. 
43. Wu, Z.; Deng, Y.; Liu, S.; Liu, Q.; Chen, Y.; Zha, F. Strength and micro-structure evolution of compacted soils modified by admixtures of cement and metakaolin. Appl. Clay Sci. 2016, 127-128, 44-51. [CrossRef]

44. Sazali, N.; Harun, Z.; Abdullahi, T.; Azhar, F.H.; Sazali, N. Revolution of Malaysia's Kaolin to Metakaolin towards various application: A Mini Review. J. Mod. Manuf. Syst. Technol. 2019, 4, 722-728. [CrossRef]

45. He, J.; Li, Z.X.; Wang, X.Q.; Shi, X.K. Durability of Soft Soil Treated with Soda Residue and Ground Granulated Blast Furnace Slag in a Soaking Environment. J. Mater. Civ. Eng. 2020, 32, 1-10. [CrossRef]

46. Yao, K.; Wang, W.; Li, N.; Zhang, C.; Wang, L. Investigation on strength and microstructure characteristics of nano-MgO admixed with cemented soft soil. Constr. Build. Mater. 2019, 206, 160-168. [CrossRef]

47. Gu, K.; Jin, F.; Al-Tabbaa, A.; Shi, B.; Liu, C.; Gao, L. Incorporation of reactive magnesia and quicklime in sustainable binders for soil stabilisation. Eng. Geol. 2015, 195, 53-62. [CrossRef]

48. National Academies of Sciences. Recommended Practice for Stabilization of Sulfate-Rich Subgrade Soils; The National Academies Press: Washington, DC, USA, 2009; ISBN 9780309429825.

49. Puppala, A.J.; Talluri, N.; Chittoori, B.C.S. Calcium-based stabiliser treatment of sulfate-bearing soils. Proc. Inst. Civ. Eng. Ground Improv. 2014, 167, 162-172. [CrossRef]

50. Chegenizadeh, A.; Keramatikerman, M.; Miceli, S.; Nikraz, H. Investigation on Recycled Sawdust in Controlling Sulphate Attack in Cemented Clay. Appl. Sci. 2020, 10, 1441. [CrossRef]

51. British Standards Institution. BS EN 13286-2:2010: Unbound and Hydraulically Bound Mixtures Part 2: Test Methods for Laboratory Reference Density and Water Content_-Proctor Compaction; BSI Standards Ltd.: London, UK, 2012.

52. British Standards Institution. BS EN 13286-49:2004: Unbound and Hydraulically Bound Mixtures Accelerated Swelling Test for Soil Treated by Lime and/or Hydraulic Binder; BSI Standards Ltd.: London, UK, 2004.

53. British Standards Institution. BS EN ISO 17892-7:2018: Geotechnical Investigation and Testing. Laboratory Testing of Soil Part 7: Unconfined Compression Test Strength; BSI Standards Ltd.: London, UK, 2018.

54. Shah, V.; Scott, A. Use of kaolinite clays in development of a low carbon MgO-clay binder system. Cem. Concr. Res. 2021, 144, 106422. [CrossRef]

55. Alsafi, S.; Farzadnia, N.; Asadi, A.; Huat, B.K. Collapsibility potential of gypseous soil stabilized with fly ash geopolymer; characterization and assessment. Constr. Build. Mater. 2017, 137, 390-409. [CrossRef]

56. Yong, L.L.; Namal Jayasanka Perera, S.; Syamsir, A.; Emmanuel, E.; Paul, S.C.; Anggraini, V. Stabilization of a residual soil using calcium and magnesium hydroxide nanoparticles: A quick precipitation method. Appl. Sci. 2019, 9, 4325. [CrossRef]

57. Estabragh, A.R.; Jahani, A.; Javadi, A.A.; Babalar, M. Assessment of different agents for stabilisation of a clay soil. Int. J. Pavement Eng. 2020, 1-11. [CrossRef] 